Portland State University

PDXScholar

$11-4-2021$

\title{
Investigating Values in Discourse: Ideals and Social Plans
}

Luke Edward Hanst

Portland State University

Follow this and additional works at: https://pdxscholar.library.pdx.edu/open_access_etds

Part of the Communication Commons, and the Social Psychology Commons Let us know how access to this document benefits you.

\section{Recommended Citation}

Hanst, Luke Edward, "Investigating Values in Discourse: Ideals and Social Plans" (2021). Dissertations and Theses. Paper 5883.

https://doi.org/10.15760/etd. 7754

This Thesis is brought to you for free and open access. It has been accepted for inclusion in Dissertations and Theses by an authorized administrator of PDXScholar. Please contact us if we can make this document more accessible: pdxscholar@pdx.edu. 
Investigating Values in Discourse: Ideals and Social Plans

by

Luke Edward Hanst

A thesis submitted in partial fulfillment of the requirements for the degree of

Master of Science

in

Communication

Thesis Committee:

Cynthia-Lou Coleman, Chair

L. David Ritchie

Lee Shaker

Portland State University

2021 
(C) 2021 Luke Edward Hanst 


\begin{abstract}
Social scientists argue that values enable group coordination. I explore two theories of values before turning to evidence provided by Amanda Gorman's inaugural poem, "The Hill We Climb.” First, the paradigm of Shalom Schwartz describes values as transsituational goals which enable groups to coordinate action and evaluate the world. I argue the Schwartz paradigm zooms out from values into categories while I need a means to zoom in to understand values in discourse. I turn to the Pragmatic Prospection paradigm to elaborate the cognitive ontology of goals and to understand the function of language. I argue that values are shared simulations of desirable futures and plans to attain them. By sharing plans in discourse, groups can coordinate action to attain goals. I employ a qualitative textual analysis using Close Reading and Conceptual Metaphor Theory to search for values in "The Hill We Climb." My analysis identifies: Ideals (and Criteria of Evaluation), Plans, Means, Ends, and Negative Social Values. Ideals are words that describe a simulation and are often used in criteria of evaluation to create a contrast between the status of the present (the real) and the desirable state (the ideal). I found that Gorman articulates a variety of plans which are demarcated by the connection of possible actions (means) with desirable outcomes (ends). Negative social values are those ideals and plans which Gorman rejects as undesirable to articulate what actions should not be taken. I provide representative examples and theoretical analysis for each category before offering a discussion.
\end{abstract}




\section{Acknowledgements}

I want to acknowledge the Native American Tribes who were forcefully removed from the lands on which I have lived and learned. I acknowledge the Klamath Tribes, including the Klamath, Modoc, and Yahooskin, on whose land I was raised from a young age. The Klamath Tribes were forced off their land onto reservations which were subsequently dissolved by the United States Congress in 1954, and only after 32 years of legal efforts were the Klamath Tribes once again recognized as a sovereign people in 1986, although their lands were not repatriated (The Klamath Tribes, n.d.). The forced removal and continued exclusion of the Klamath Tribes from their traditional homelands is the grim foundation for my childhood home overlooking the Klamath Lake.

I acknowledge the Clackamas and Multnomah Peoples on whose lands now rests the City of Portland where this thesis was written. The Clackamas and Multnomah tribes were a few thousand strong before diseases introduced by settlers and traders decimated their population by as much as 90\% (The Oregon History Project, 2018). The few remaining people of the Multnomah were relocated to the Grand Ronde Reservation (National Geographic, n.d.). In consideration of the history of the region, I want to acknowledge the resilient Native American communities still in Multnomah County who live with the effects of colonization. These peoples were denied citizenship until 1924, they were denied the right to vote until 1965, their faith traditions were outlawed until 1993, and their children were taken into boarding schools until 1978 - as of 2011, Native American children living in Multnomah County are over twenty times more likely to be removed from their parents care than White children (Curry-Stevens, Cross-Hemmer, \& Coalition of Communities of Color, 2011). Today, these communities continue to face 
disproportionate rates of poverty, houselessness, and medical neglect (Curry-Stevens et al., 2011).

I am also forever grateful to Cynthia Lou-Coleman, the chair of my committee, for her unwavering support, knowledge, and friendship on my journey. I have had the pleasure of working with Cynthia for the past four years, both in and out of the classroom. Her guidance has shaped my academic career in immense and unknowable ways. Thank you so much Dr. Coleman. And thank you Dr. Ritchie and Dr. Shaker for your guidance throughout my research process.

Thank you, Amanda Gorman, for stepping up in a time of great hardship to offer a shining light in the dark, and to offer leadership to the people of our great nation. Thank you to all the medical staff of America for keeping me, my family, and my communities safe through the COVID-19 pandemic.

Thanks to my roommates for offering their ears for many hours of discussion and venting. Thank you to my graduate cohort, Ultimate Frisbee teams, and friends for always encouraging me and believing in me. Thank you to my wonderful partner Hannah for your unwavering support and compassion. Without you I would have crumbled many months ago. Thank you to my parents, siblings, grandparents, aunts, uncles, and cousins for raising me to be who I am today, and for providing me with examples of how to be a good person. And an honorable mention to bone broth and bread for healing my soul and rejuvenating my mind in these times of isolation. 


\section{Table of Contents}

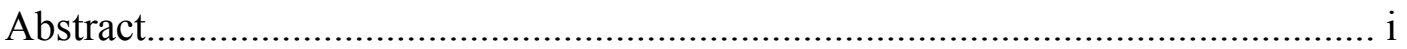

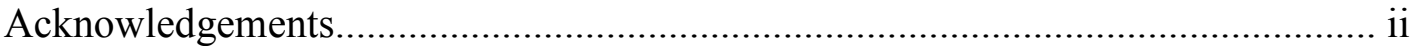

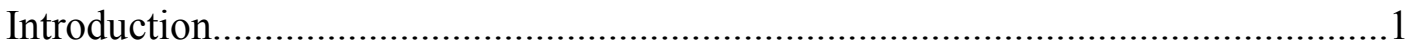

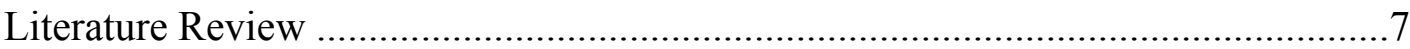

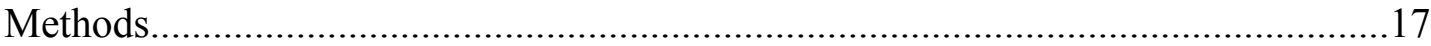



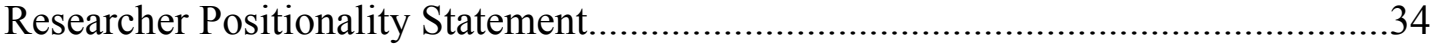

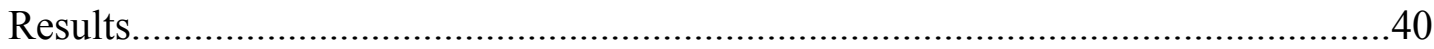

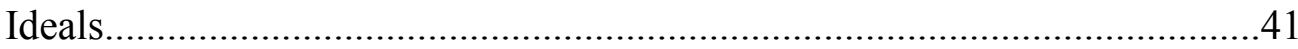

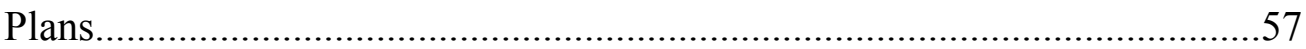

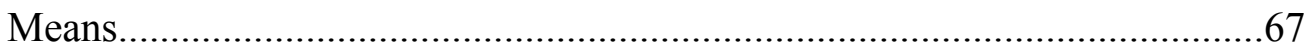

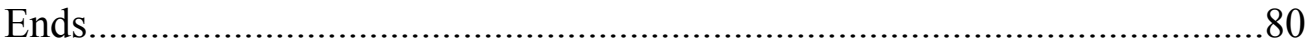

Negative Social Values...................................................................... 90

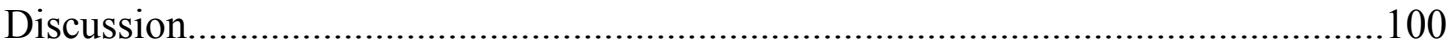

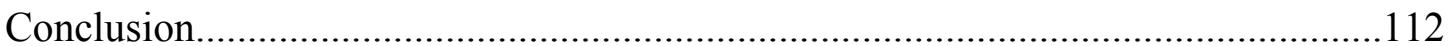

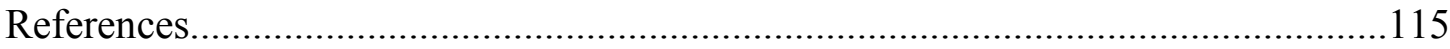




\section{Introduction}

Scholars argue that social values are goals that coordinate action across

individuals and serve as the basis for assessments of good and bad (e.g., Joas, 1997/2000;

Rokeach, 1973; Schwartz, 1999). In this thesis, I embark on an exploration of social values at an important political-historical moment in America, the 2021 inauguration of President Joe Biden. Specifically, I investigate Amanda Gorman's inaugural poem, "The Hill We Climb" (2021). My investigation of values espoused in this poem participates in the social reflection on America's moral framework by drawing out and interpreting some of Amanda Gorman's vision for our nation's future.

Presidential inaugurations are moments in which the incoming presidential administration seeks to unify the country behind a leader (Campbell \& Jamieson, 2008). To accomplish this objective, inaugural rhetoric tends to reflect on the problems facing the nation while articulating traditional values intended to guide the nation's future action (Campbell \& Jamieson, 2008). It is the function of inaugurations to unify the nation by reflecting on cultural values, and it is for this reason that I take Gorman's poem as the site of my investigation. Within the poem, I find myriad social values concerned with unifying the citizens of America behind shared goals and acceptable plans for action.

In my search for values within "The Hill We Climb," I begin with a literature review that digs into the scholarship of how values are conceptualized and operationalized. This process starts with an exploration of the work of social psychologist Shalom Schwartz and his theory of basic human values. Schwartz, and before him Milton Rokeach, define values as socially available beliefs about the desirability of certain actions or outcomes, what Schwartz calls transitional goals (Rokeach, 1973; Schwartz, 
2012). These values are, according to Schwartz's theory, necessary for groups so they can articulate shared goals that enable coordination and cooperation. Values within this paradigm also serve as criteria of evaluation. That is, individuals and groups use values to make sense of elements of the world as good or bad. Based on this conceptualization, Schwartz and colleagues have developed a universal typology of value domains into which all social values should fit (Schwartz, 2012).

At this point in the literature review, I provide a brief argument that the objective of the Schwartz paradigm of values is to zoom out from values to examine the relationship between value categories. However, for my investigation of values in discourse, I need a means to zoom in and understand the linguistic meaning of values. So, to equip my analysis, I pull a thread from Schwartz's theory into the realm of neurology in hopes of identifying a concept of values which is sensitive to the human capacity for language. That is, I follow the thread of goals and ask: how do goals manifest in human cognition and what role does language play?

To answer this question I turn to neurologists, social psychologists, and sociologists under the general banner of Pragmatic Prospection. This literature review section advances the theory of goals while also functioning as a point of contrast for the Schwartz paradigm. In this section of the literature review, I argue that the human mind can simulate possible future situations in which the mind identifies goals, or desirable outcomes, and devises plans to attain them. These shared goals and plans are experienced as perceptual simulations which are conveyed within groups via language. I argue that these goals and shared plans are social values which enable the coordination of action between individuals. 
Having arrived at a clearer theoretical understanding of the expected form and cognitive experience of social goals, I then introduce methods for approaching my research question: How do values manifest in "The Hill We Climb"? To address this question, I opt for a qualitative methodology because it enables me to bring theory and evidence into dialogue with one another. Qualitative analysis is based on principles of empathy and reflexivity, which I present in a researcher positionality statement and a background investigation of "The Hill We Climb.” Using the principles of qualitative analysis, I employ the methods of Close Reading and Conceptual Metaphor Theory that scholars use for textual analysis. Close Reading methods prepare me to read a text and discern meaning from the linguistic and grammatical choices of the author. Conceptual Metaphor Theory, on the other hand, is well suited to investigate perceptual simulations as the theory argues that speakers use conceptual metaphors as a resource to spark perceptual simulations and explain complex social phenomena in terms of simpler, more universal experiences. After outlining these methodologies and methods, I discuss the polysemic nature of texts as a research limitation.

Searching for values in "The Hill We Climb" proved to be an iterative process. I began by familiarizing myself with the text through multiple readings. I then highlighted words or phrases that seemed to correspond with the values literature. I returned to each section I highlighted and applied theory to derive a reading of that section. Using the literature as a guide, I divided the values into the following categories: Ideals (and Criteria of Evaluation), Plans, Means, Ends, and Negative Social Values. My analysis describes each of these categories, provides representative examples, and offers theoretical implications. 
Ideals are specific words that refer to a belief or social construct which may be desirable. The ideals identified in "The Hill We Climb" conform to traditional value words expected by the Schwartz Value Survey (e.g., Peace or Justice), but they also surpass those traditional expectations through conceptual metaphors (e.g., Polished or Pristine). Ideals describe the quality or state of simulations and are very often used as criteria of evaluation. That is to say, throughout the poem Gorman uses grammar to identify and evaluate the status of the present or past according to its congruence with or departure from the ideal state conveyed by the value word.

In my discussion of ideals, I suggest that the theoretical expectations provided by the Schwartz paradigm can include words beyond what is currently contained in the Schwartz value survey. This necessitates either a more inclusive, grounded method to identifying values in the social world, or the continued clarification of conceptual boundaries to distinguish between traditional and non-traditional ideals.

Plans manifest within "The Hill We Climb" as articulated chains of causality concerned with directing future action towards the attainment of a goal. Plans connect possible actions, what I call means, with desirable outcomes, or what I call ends. The quantity or complexity of relationships between possible actions and desirable outcomes ranges from very short plans to multi-step plans. Means within the poem very often rely on conceptual metaphors that invoke simulations of physical actions to refer to the complex social behaviors necessary for the attainment of the goal. Plans, means, and ends often refer to each other or rearticulate one another, and through this reference and rearticulation, Gorman can clarify and expand on the actions and desired outcomes. 
I present evidence for two emergent types of plan components. The first I call standards, which occur when an ideal is situated as necessary means for the success of a plan. For example, Gorman posits that success in achieving collective objectives demands that the people of America achieve success according to the criterion of bravery. I argue that standards can serve as a bridge between Schwartz's theory of values and Pragmatic Prospection's argument for the function of consciousness to plan action. The second emergent plan component I call end matrix, which are words or phrases situated as the end-goal for action that refer to a great many outcomes simultaneously. For example, I argue that the term victory refers to success in multiple social realms as indicated by the discursive context. End matrices capitalize on the metaphorical nature of language and enable a speaker to draw connections between certain actions and multiple desirable outcomes simultaneously.

In the discussion of plans, means, and ends, I argue that conceptualizing values as socially shared simulations of possible future situations in which we identify goals and devise plans to attain them can help researchers investigate the foundations for coordinated group action. Values as shared understandings of the desirable future may align peoples' frames of reference, and therefore researchers should continue to investigate how these values become adopted and how different individual perspectives can constrain or contribute to the understanding and attainment of shared objectives. I add that the Pragmatic Prospection paradigm should adopt a system of notation and conceptual language to demarcate plan components, which will assist in the investigation of forms of plans and the interaction of plans with language and technology. 
The final category of values which emerged from the text are negative social values, which demonstrate the theoretical capacity for values to refer to the undesirability or badness of certain actions, goals, or plans. I argue that negative social values in "The Hill We Climb" abide a similar theme of rejecting regressive ideologies and nostalgic orientations to political objectives. Through this theme we see a reflection of Gorman's evaluation of America's political landscape. My discussion asserts that continued investigation of negative social values may shed light on group processes for the prohibition of certain behaviors and the coordination of action in opposition to undesirable outcomes.

For the theory of values more generally, my results suggest that there is work to be done to identify and disentangle all the different concepts wrapped into the term values. By developing a typology of value concepts, scholars will be better equipped to understand the differing functions and interactions between, say, values as ideals and values as desirable ends. Such a typology may also improve methodological clarity. By demarcating the intention or utility of certain value concepts, scholars can ensure responsible use and better discuss the different ontological and epistemological assumptions that influence the research process. Clarification of the intention and utility of value concepts will bolster research occurring at the nexus between individual psychology, group culture, and language by focusing concepts on their respective domains while enabling better understandings of the interplay between them. 


\section{Literature Review}

Much of the empirical research into social values over the past 30 years stems from the theory provided by Shalom Schwartz. Schwartz is a social psychologist whose professional research career began in 1967 at the University of Wisconsin-Madison before he moved to Israel in 1979, where he worked in the psychology department at the Hebrew University (Schwartz, 2019). In Jerusalem, Schwartz began a lifelong investigation of his theory of basic human values. I draw on Schwartz's theory of values to spearhead my investigation of Amanda Gorman's poem.

Understanding the Schwartz value concept requires a cursory investigation of Milton Rokeach's contributions. Rokeach claimed an almost perfect monopoly on the empirical study of values after his seminal publication of the Rokeach Value Survey in 1973. His book, The Nature of Human Values (1973), was considered without rival: "no competitors... took on the paradigmatic status" (Zenzen \& Hammer, 1978, pp. 142-143). It was not until 1992 with the official release of the Schwartz Value Survey that Rokeach's dominance began to transition to a younger scholar and a younger generation of researchers. From 1992 until today, Schwartz's theory of values has remained “predominant in psychology” (Cieciuch et al., 2015, p. 41).

Rokeach (1973) defined a value as "an enduring belief that a specific mode of conduct or end-state of existence is personally or socially preferable to an opposite or converse mode of conduct or end-state of existence" (p. 5). Values in this sense are “priorities" for modes of conduct (i.e., behaviors or means) and end-states of existence

(i.e., outcomes or ends; Schwartz, 2012). Example modes of conduct include: "Clean," "Ambitious," "Capable;" and example end-states include: "A Comfortable Life," 
"Happiness," "National Security" (Rokeach 1973, p. 28). Rokeach argued that Instrumental values are the "modes of behavior" necessary for the "realization" of Terminal values, i.e., end-states (p. 49). Values as such are a cognitive prioritization of certain means intended to bring about desirable ends.

Schwartz retained the terminology of "modes of conduct" and "end-states" explicitly through at least 1992 (Schwartz \& Bilsky, 1987, p. 551; Schwartz, 1992). In subsequent years, Schwartz transitioned the definition of values to: "transsituational goals" (e.g., Schwartz et al., 2012, p. 3). Schwartz argues that transsituational goals, “convey what is important to us in our lives" (Bardi \& Schwartz, 2003, p. 1208).

Transsituational goals are "implicitly or explicitly shared abstract ideas about what is good, right, and desirable in a society" (Schwartz, 1999, p. 25). Schwartz here is trying to negate the division of means and ends to focus on the social construct which is being prioritized.

The theoretical redefinition of values as "transsituational goals" was premised on Schwartz's and Bilsky's (1990) argument that the division between means (instrumental values) and ends (terminal values) "is not clear-cut," because "an end can readily become a means and vice versa" (p. 879); an argument credited to John Dewey's "later writings" (p. 879). Empirical evidence for the consolidation of means and ends was garnered from college students who failed to distinguish values into Terminal versus Instrumental categories (e.g., distinguishing the word "Clean" from the word "Happiness;" Schwartz \& Bilsky, 1990). So, Schwartz attempted to overcome the division of means and ends by subsuming both into the same concept of transsituational goals. 
I question the validity of Schwartz's argument here. It seems the decision to merge means and ends into the same concept stems more from the methodological instrument used than from the lived reality of the participants. The empirical data for Schwartz's argument come from a sample of students who were unable to distinguish between the 32, one-word, value objects of the Rokeach survey instrument, which relies on the assumption that values are only single-word objects that exist without context (e.g., friendship and freedom; Schwartz \& Bilsky, 1990). Furthermore, just because means can become ends does not make the conceptual division useless. Research into values should acknowledge the possibility that desirable end-states can depend on the means available to their pursuit. An example is the value of a long and healthy life. Each individual striving for this goal has identified different practices that they believe will lead to health and well-being. Goals can specify and elaborate on means which are meant to help attain the goal, and understanding the means chosen to pursue the desired end will lead to more valid research.

Regardless of the status of means and ends, Rokeach and Schwartz agree that individuals use values to make sense of the world. By that I mean to say, values function as "criteria of evaluation" (Bilsky \& Schwartz, 1994). Because values are goals which matter for our lives, they serve as markers to judge other people, things, or events. Values, in this sense, provide the foundation for valuation processes: people discern goodness or badness, in light of their values.

Both Rokeach (1973) and Schwartz and colleagues (e.g., Schwartz \& Bilsky, 1987; Schwartz \& Sagiv, 1995; Cieciuch et al., 2015) are interested in a universal theory of human values. While Rokeach was interested in devising a list of universal values, 
Schwartz premises the universality of his value concept on three universal requirements which face each social group. These requirements are the: "needs of individuals as biological organisms, requisites of coordinated social interaction, and survival and welfare needs of groups" (Schwartz, 2012, p. 4). Schwartz's argues that: "from an evolutionary viewpoint, these goals have crucial survival significance," and in order to meet these universal needs "people must articulate appropriate goals to cope with them, communicate with others about them, and gain cooperation in their pursuit" [emphasis added]; (Schwartz, 1992, p. 4; Schwartz, 2012, p. 4). Individuals and groups use values to "represent these goals mentally" and to "express them in social interaction" (Schwartz, 2012, p. 4). ${ }^{1}$ These theoretical passages are essential for my thesis as they make explicit that social values are a psychological belief, but that these values do, indeed they must, manifest in discourse. Therefore, exploring how social values manifest in discourse is a relevant avenue to make sense of Schwartz's argument for the universality of values. Schwartz argues that the universal requirements serve as bases from which myriad motivational value domains spawn. Value domains, according to Schwartz's theory, form a circular continuum of motivations in which all value items will fit. This continuum is said to represent the "structural organization of value systems" based on “consistent patterns of compatibility and conflict among value types" (Schwartz, 1992, pp. 2,47$)$. In other words, giving priority to a certain type of value makes it more "practically feasible" to prioritize nearby values while it would be "contradictory" to prioritize values from distant motivational domains (Schwartz \& Bilsky, 1987, p. 550). The degree to which prioritizing value domains is incongruent is reflected in the

\footnotetext{
${ }^{1}$ The results section on Ideals discusses how Schwartz's social values appear to manifest in discourse.
} 
domain's degree of separation in the circular value diagram. Values that are on opposite sides of the circle are the most incompatible, and adjacent values are the most compatible (e.g., Schwartz et al., 2012).

In summary, values are socially constructed beliefs about what is important, good, or desirable. These beliefs are transsituational goals; they transcend any one situation and serve to guide decision making and valuation processes. Schwartz argues that operationalizing values does not require consideration of means or ends, but I have outlined a counterargument which encourages further empirical investigation on this matter. Values are individually held but socially constructed. That is, people learn values through socialization processes during which the individual internalizes beliefs from their social sphere about what desirable end-states are and how they can be attained (Hitlin, \& Piliavin, 2004). When individuals share values, they uphold the fabric of group life and can coordinate action to achieve collective goals (Schwartz, 2012).

Because values allow groups to coordinate action and uphold the social fabric, scholarship is often concerned with the function of values in maintaining nation-states (e.g., Rokeach, 1973). Campbell and Jamieson (2008) argue that presidential inaugurations in the United States serve as a ritualized moment of discourse intended to unify the country and reflect upon traditional values. During inaugurations, presidents preach social values to unify the people of America behind collective goals. During President Joe Biden's 2021 inauguration, Amanda Gorman presented the $6^{\text {th }}$ inaugural poem which speaks to America's past, present, and future. I take her poem, "The Hill We Climb," as my site of empirical investigation and ask: 
Research Question: How do values manifest in Amanda Gorman's inaugural poem, "The Hill We Climb”?

\section{Operationalizing Goals}

Schwartz, and before him Rokeach, relied on a survey instrument to garner empirical evidence for the development of theory. The Schwartz Value Survey, for example, uses 56 value words, 21 of which were retained from the Rokeach Value Survey, the remainder were derived to "represent each type" of value domain (Schwartz, 1992, p. 17). Participants are asked to rate each value on a 7-point Likert scale, and the correlations between prioritized value words, taken in the aggregate, represents the underlying value system of a culture. In effect, the operationalization of the Schwartz paradigm has zoomed out from abstract value words to identify the structural relationship of these value words (e.g., Schwartz, 2012).

I argue that Schwartz's list of values approach is insufficient to investigate how values manifest in discourse, and risks misrepresenting values in "The Hill We Climb." Rather than zoom out to value categories, I need a means to zoom in to investigate the meaning of values as they are used in a linguistic scenario. Language and discourse are intimately connected to human cognition, and to identify values in discourse requires an operationalization that is sensitive to this cognitive ontology. In pursuit of such an operationalization, I ask: How do goals manifest in human cognition and what role does language play?

In this section, I propose an expansion to the conceptualization of goals to arrive at an operationalization more well suited for the investigation of discourse. To do this, I situate goals within neurological theory and the framework provided by Pragmatic 
Prospection (e.g., Seligman, Railton, Baumeister, \& Sripada, 2016). A rough sketch of my argument is as follows: Life is fundamentally goal oriented, and human consciousness has transformed these goals into social constructs. Per the Pragmatic Prospection framework, goals are perceptual simulations of possible future situations in which people identify desirable outcomes and devise plans to attain them. Discourse enables the construction of a shared vision for the future alongside shared plans to achieve a group's goals. These social goals and plans can be considered social values which enable the coordination of action between individuals.

All living organisms have a drive to continue life, and this serves as the most fundamental transsituational goal (Damasio, 2018; McGann, 2007). Living organisms are "embodied" knowledges which maintain an awareness of, and motivational pull towards, a vaguely desired state-of-being which is better than the present (Atzil et al., 2018, p. 627). Damasio (2018) argues that the organism's mind maintains a representation of the present status of the body alongside a representation of the expected future state of the body, and these representations drive animals to perform actions which will improve the status of the present and future. The goal-states of organisms were non-linguistic and purely physiological until human consciousness harnessed language to become aware of group objectives (McGann, 2007). A capacity for language enables the human mind to articulate and create ideas about what the goal state for action is (Atzil et al., 2018; Seligman et al., 2016). Furthermore, the linguistic creation of goal-states allows cognition to extend the representative capacity of the present and future to larger social groups, allowing action to be directed towards the collective welfare (Damasio, 2018). 
Cognition is teleological in nature: our minds simulate potential futures which serve as the end-objective for the direction of action (Baumeister et al., 2016; Damasio, 2018). Baumeister et al. (2020) provide empirical evidence that the human mind coordinates the person through time. ${ }^{2}$ These studies argue that human cognition is most often goal oriented: we are concerned with the meaning of the past for our goals; we are concerned with the present moment to ensure we stay on track towards our goals; and we contemplate the future to set goals and devise plans to achieve them. Thinking about possible future situations and potential outcomes allows people to plan behavior and increase the likelihood of successful action. The mind constructs a "matrix of maybe," a collection of possible futures and potential intervention points at which skillful action could shift the trajectory of events to one's favor (Baumeister et al., 2020, p. 1632).

Through communication people can share goals within a social setting, and these come to represent shared group "purposes," which "involve the setting of very long-term goals and the (more-or-less) systematic march towards them" (McGann, 2007, p. 480). These group purposes (i.e., values) become the teleology used by individuals within a group for the direction of action in the present and the foreseeable future. When values are shared, people within a group can cooperatively perform physical and linguistic actions to achieve a mutually adopted goal state.

\footnotetext{
${ }^{2}$ In one study, participants were prompted to use a smartphone application at random intervals throughout the day to report their most recent thoughts. Results suggest that $20 \%$ to $35 \%$ of thoughts are concerned with the future, about $10 \%$ are concerned with the past, and the remaining $55 \%$ to $70 \%$ are about the present. The researchers investigated the content of these thoughts with closed-ended survey questions. Results indicate that thoughts of the past are often concerned with making sense of the past and understanding its implications for the future. Thoughts in the present are most often concerned with surveillance of ongoing activities (e.g., "doing what I intend to do," Baumeister et al., 2020, p. 1639). And future thoughts are almost always $(75 \%)$ about planning future behavior.
} 
The future, and our planning for it, involves us knowing the imagined potentiality is yet to arrive while formulating ideas about what events, if they occur, could lead from the present moment to the idealized future (Baumeister et al., 2016). Cognitive simulation of future realities re-deploy and reuse the physiological processes associated with the construction of mental experience in the present (Baumeister et al., 2018). Extended deliberation and planning about the future occur as perceptual simulations: metaphorical "short films that the brain makes for itself" (Baumeister \& Masicampo, 2010, p. 945).

The construction of potential futures occurs in discourse within groups. It is language which enables the creation and sharing of goals (Baumeister, 2016). Words incite perceptual simulations and enable people to share and co-construct simulations of realities that do not yet exist but could be brought into being through the appropriate actions. Language also allows for the lessons of past experiences to help guide the construction of goals in an emergent situation. Functionally speaking, language allows us to communicate simulations of possible futures and therefore to communicate social values.

In summary, people simulate action situations wherein they imagine desirable outcomes and then devise means to achieve those ends. Human cognition experiences social values as perceptual simulations. Language enables people to co-construct simulations of potential futures and plans of action to attain these goals, in essence, creating and sharing values. Mutual adoption of a desirable future enables members of a group to coordinate their actions towards the attainment of these social goals. 


\section{Presidential Example of a Desirable Future}

Because I am interested in how values manifest in "The Hill We Climb," I will examine simulations of desirable futures. I expect that desirable end states will be wrapped up in the means Gorman believes will achieve the goals. An example of this sort of value can be seen in U.S. President Joe Biden's 2021 inaugural speech when President Biden said, "The American story depends not on any one of us, not on some of us, but on all of us, on 'we the people' who seek a 'more perfect union'” (Biden, 2021, n.p).

This passage links a goal with the means that might attain it. The goal of the narrative is to create "a more perfect union," and the means to attain this goal is a coming together of "all of us, on "we the people."” This passage outlines the relationship of a means with the desirable end, and President Biden continued to clarify the end-goal when he noted: "a cry for help comes from the planet itself" (Biden, 2021, n.p.) This statement elaborates on the meaning of "a more perfect union" by invoking ideas of a future wrought by climate change. Failure to deal with global warming would undercut the economic and political stability of America. "A more perfect union" is, then, a future in which climate change has been curbed and our ecosystems stabilized. President Biden argues that this future state of the union can be attained through cooperation and collective action.

In summary, I will search for values in Gorman's poem as simulations of desirable futures, and I am interested in the plans proposed to bring these futures into existence. I continue to discuss operationalization in the Methods Section. 


\section{Methods}

I take Amanda Gorman's inaugural poem, "The Hill We Climb," as the research object for an empirical investigation of values. Gorman's poem provides an opportunity to explore social values within a clearly delineated text that was presented at an important moment in American political history: President Biden's inauguration. Campbell and Jamieson (2008) describe U.S. inaugurations as a ritualized discursive event during which incoming presidential administrations typically intend to unify the audience and articulate "communal values drawn from the past" (p. 30). As such, I expect "The Hill We Climb" will be flush with values.

I analyze "The Hill We Climb" through a qualitative lens. Qualitative analysis is a reflexive process of investigation in which the scholar brings theory and data into dialogue with one another. The work of science thereby creates new knowledge from the interactions between the researcher and the empirical world (Hesse-Biber, 2017). Rigorous qualitative research depends on the combined practices of empathy and reflexivity, and I outline both below. Guided by these principles, I employ methods drawn from Close Reading and from Conceptual Metaphor Theory to dissect the text. Using a qualitative approach as a substitute to a quantitative values survey ensures the investigation will remain flexible to emergent theoretical themes and will enable me to avoid undue reduction of the empirical data.

Through empathy the researcher can use skillful practice during the "co-creation" of knowledge to center the voice of the researched (King et al., 2019). Bednarek-Gilland (2015) defines empathy as “imagining ourselves in the other's shoes in order to achieve an understanding of their meaning" (p. 40). She argues that empathy can be bolstered by 
time spent with the researched and by learning more about the subject's context and history. I practiced empathy by attempting to center Amanda Gorman's perspective when evaluating the poem. That is, I worked to see America through the eyes of a "skinny Black girl, descended from slaves and raised by a single mother" (Gorman, 2021, p. 14), and I worked to understand Gorman's poem through the same set of eyes.

Reflexivity is the process of recognizing and understanding how the researcher's point of view has influenced the research process (Holmes, 2020). By using reflexivity, a researcher can attempt to understand their positionality through "self-assessment" (Holmes, 2020, p. 2). The researcher's positionality enters the research process in all stages from the selection of the project to the presentation of results, and whenever possible the researcher should be forthcoming with such influences. Holmes (2020) argues that a researcher can implement reflexivity by locating themselves according to the object of research. During the drafting of final research transcripts, a researcher may provide a positionality statement in which the "researcher's lenses" are disclosed (Holmes, 2020, p. 4). Holmes (2020) recommends that a positionality statement covers "philosophical, personal, [and] theoretical beliefs," alongside characteristics of the researchers which may come into play like "age, political beliefs, social class, race," etc. Finally, the positionality statement should outline the "research-project context" with its potential influences (p. 4). I employ this format in the forthcoming positionality statement.

Linguists provide the practice of Close Reading to discern meaning through "attention to the... rhetorical devices of language" (Culler, 2010, p. 21). I rely on a "poetic," or hermeneutic, process to dig into "how meaning is produced or conveyed" by 
the text (Culler, 2010, p. 22). McIntosh and Cuklanz (2017) note that qualitative scholars can attend to the meanings of a text through attention to elements of language like terminology, metaphors, and grammar. So, Close Reading refers to the careful process of unpacking and exploring a textual document to assess the meanings it conveys. I map out "The Hill We Climb" by paying attention to the elements of grammar, narrative, and metaphors.

Conceptual Metaphor Theory posits that human cognition can understand and experience complex social concepts in terms of less complex concepts associated with more universal experiences (Ritchie, 2017; Ritchie, in press). Conceptual metaphors are a "resource" available in the articulation of social experiences (Ritchie, in press).

Metaphorical concepts and language can be strung together by an individual into a larger metaphorical story. A metaphorical story is elaborated through successive lines of discourse into a complex cognitive simulation in which each additional metaphor modifies in some way the simulated reality (Ritchie, in press). For example, Amanda Gorman's poem, “The Hill we Climb," reads: "We've seen a force that would shatter our nation, rather than share it." The four words: "seen," "force," "shatter," and "share" stand out as the conceptual metaphors in this passage. A force, for example, is a physical concept which Gorman may be using to refer to the insurrectionists of January $6,2021 .^{3}$ As this brief example shows, conceptual metaphors enable Gorman to discuss complex macro-political happenings with everyday experiences.

\footnotetext{
${ }^{3}$ Discussed in the Background for "The Hill We Climb" section. The insurrection of January 6, 2021 involved hundreds of protestors breaking into the U.S. Capitol building to halt Congress's counting of the electoral college votes.
} 


\section{Limitations}

The polysemic nature of text is a key limitation to my methodological approach. Texts are polysemic: "they always contain a multitude of potential meanings," and it would be impossible for the researcher to identify every possible reading (McIntosh \& Cuklanz, 2017, p. 249). By this logic, my perspective on the text may miss readings which would have been available to a researcher with a different positionality. There is an added risk of reading into the text tautologically (i.e., deriving more from theory than from empirical evidence). Matthes and Kohring (2008) argue that a researcher can mitigate these risks by providing detailed empirical evidence from which the reader can assess validity.

In the final stages of my analysis, polysemy presented a challenge for presenting my results. My research looks at the use of ideals as criteria of evaluation along with simulations of possible future situations and the linguistic creation of plans to pursue these goals. A problem arose when it became time to re-articulate what a particular value means. After serious consideration I decided that the fluid nature of words and their meanings is not the focus of my research question, and while I must recognize the inherent polysemy of Gorman's words, I must also be able to focus on the manifestation of values as a social phenomenon. Towards this end I adopted the following framework for interpreting the language of the poem.

First, I provide the literal definition(s) of Gorman's chosen words from the Oxford English Dictionary, what I call the denotation. Then, I provide what I think the words mean in the present discursive context, what I call the connotation. I bring these two perspectives into a dialectical interaction and try to convey a reasonable reading of 
the text. In a similar sense, when the poem relies on conceptual metaphors, I explore the basic concept conveyed by the word before extrapolating to the social phenomenon it seems to reference. I do not claim or desire for this to be an objective reading of the text, yet I am confident this method enables me to present Gorman's words in a coherent fashion.

\section{A Note on the Source Text}

I used the official book The Hill We Climb: An Inaugural Poem for the Country released by Gorman in 2021 as the source text for research. The published booklet provides a more authoritative reading of the poem compared to transcripts provided by news sources or transcriptions of the spoken word presentation. Different sources for the text contain different words or punctuation and might therefore carry different meanings. For example, the CNBC transcript provided by Liu (2021), includes an added line: "become the future." In another instance, multiple newspaper transcripts placed quotations around the word "just" while Gorman's official text places quotes around "just is," which can lead to different readings of the text. Other inconsistencies across transcripts included a variety of grammatical differences including commas, colons, quotations, etc. It is beyond my scope or intention to explore the potential differences that arise from these inconsistencies, so I have instead opted to investigate the official version of the poem.

Gorman's presentation of her poem on the day of the inauguration can aptly be described as a performance in which the choice of clothing, gestures, and setting all communicate meaning alongside the language, cadence, and tone of the spoken poem. The cultural and emotional power of Gorman's poem was amplified under the conditions 
of its presentation, and the context of its reception by the audience. Many people I have spoken to report they were brought to tears or otherwise physically affected by the performance. So, I recognize what is lost when I say that an analysis of these additional variables is outside of the scope of this thesis. I do not consider non-verbal gestures, Gorman's choice of clothing, the setting, or the tonality and musicality of Gorman's presentation, and instead I focus solely on the words and phrases provided in the official source text. This decision stems from a lack of personal expertise and from time constraints that hinder my ability to both develop the necessary expertise and then apply it in an adequate fashion.

Readers of the results section will note another shortcoming in my interpretive lens. I am not trained nor practiced in the interpretation of poetry, and this thesis was never intended to be an examination of the influence of poetic elements on the articulation of values. As such, my investigation provides scant discussion on the influence of, for example, alliteration, antimetabole, or language play more generally. One major element of poetry which I do focus on is the use of metaphorical language which pervades the text. Even here, however, my approach is narrow and focuses on conceptual metaphors while missing or ignoring many potential references. Future research should investigate how the performative presentation of language and poetry intertwines with the creation and articulation of values.

\section{Investigating "The Hill We Climb"}

I began my investigation of "The Hill We Climb" by reading and re-reading the text many times to familiarize myself with its language and narrative. During these initial readings, I focused on making sense of the poem as I tried to understand what sort of 
story the poem tells. I identified key sections of the poem and I discerned how connections between sections convey a narrative. After I was comfortable with the narrative flow, I marked areas in the text which seemed to exude some element of values theory. During these readings I also noted apparent valence, indications of good or bad, within the poem. When exploring valence, the concept of criteria of evaluation helped me identify one-word value objects within the text, which I discuss in the results section on Ideals.

After searching the poem for all manifestations of values, I explored each value in isolation by considering the grammar, metaphors, and poetic elements to formulate a reading of that section of the poem. I also employed the theoretical concepts outlined in the literature review to explain what each identified value was, how it worked, and what outcomes it created. The many pages of notes derived from analyzing each appearance of a value served as data from which I drew out theoretical themes and representative examples. This analysis involved a dialectic between theory and data through which I arrived at the following categories of values: Ideals (and Criteria of Evaluation), Plans, Means, Ends, and Negative Social Values.

Once I had formulated the list of theoretical categories and assigned each manifestation of a value into a category, I proceeded to the final stage of analysis which involved synthesizing findings into a results section. During this stage, I developed articulations which convey what each category of values represents based on the data. Each results section describes the data and explores what the data show about the theoretical category. I then provide a few of the most interesting or representative examples to convey the essence of each category. It was during this phase that the 
framework of denotation, connotation, and conceptual metaphor analysis was implemented as it became necessary for me to explain the meaning of the examples. Once I had explained each category and provided examples, I conducted an analysis of each category to discern theoretical outcomes. 


\section{Background of "The Hill We Climb"}

Amanda Gorman was born March 7, 1998, and at 22 was the youngest poet to have participated in a U.S. presidential inauguration (Alter, 2021). Gorman was raised in Los Angeles, California, by her single mother who encouraged Gorman to pursue her interests in reading and writing, and Gorman recalls that Toni Morison's The Bluest Eye awakened her to the power of Black authors (Hassan, 2018). Throughout her life, Gorman has played a role as an activist and organizer. At 16, Gorman founded a nonprofit intended to "provide creative writing opportunities for underserved youth" (Petronzio, 2017, n.p.). While at Harvard, Gorman studied sociology and participated in social justice work centering issues of race, gender, and the environment (Holthaus, 2021; Petronzio, 2017). Gorman was selected as the first National Youth Poet Laureate in 2017, a position granted for "literary talent" and "community engagement" (Petronzio, 2017, n.p.). As the Youth Poet Laureate, Gorman organized a nationwide poetry contest centered on the climate emergency (Holthaus, 2021). Gorman's identity as a Black woman immersed in social movements indicates a personal understanding of systemic injustices and existential threats which confront the United States.

\section{An Inaugural Poem}

Campbell and Jamieson (2008) characterize U.S. presidential inaugurations as a ritualistic moment of discourse. The traditional theme of an inauguration is one of unity. Presidents seek to heal the country following the campaign season, and the goal is to transition from campaign rhetoric to a presidential rhetoric fit to lead the entire nation. Inaugural ceremonies strive for unity by bringing the "past and future" into "present contemplation" (Campbell \& Jamieson, 2008, p. 30). Presidents reflect on the state of the 
country and articulate "communal values" to align the people behind a more singular purpose (Campbell \& Jamieson, 2008, p. 30).

Amanda Gorman is the sixth poet to present at a U.S. presidential inauguration. In preparation for "The Hill we Climb," Gorman researched previous inaugural poets (Inskeep, 2001). Past inaugural poems were moments for the community's voice to be heard, and these poems reflected on the state of the nation while working to envision a brighter future (Inaugural Poems in History, 2021). Inaugural poems match the theme of inaugurations and reflect on a shared history to unify the nation to succeed in the trials to come.

First Lady Jill Biden and the incoming administration invited Gorman to write a poem for the inauguration on the theme of unity (Alter, 2021). Gorman reported having worked on her poem, "The Hill We Climb," in the last days of December 2020 and the first days of January 2021. Progress was initially slow, Gorman recounted, but the insurrection of January 6, 2021, spurred her to purpose and Gorman completed the poem that night (Bykowicz, 2021). When faced with the dire state of the nation, Gorman turned to the past for guidance. In an interview, Gorman said she turned to the "writers and orators throughout history... who are speaking within a divided America but speak of a united America" (Inskeep, 2021, n.p.). Gorman's list included Fredrick Douglass, Abraham Lincoln, Martin Luther King, and "even a lot” of Winston Churchill (Inskeep, 2021, n.p.). Spurred on by the events at the Capitol, Gorman said she sought to "envision a way in which our country can still come together and can still heal" (Alter, 2021). Inaugurations seek to heal a wounded nation by unifying the people around a consistent cause. My analysis of "The Hill We Climb," suggests that Gorman succeeded 
in writing a poem which reflects on America's collective past, makes sense of the present moment, and articulates social values which can guide the nation into the future. So, what is the state of the country that President Joe Biden and Amanda Gorman sought to unify, and what are some of the values proposed to carry the country forward?

Gorman's narrative uses metaphorical language to encapsulate a variety of the hardships America faces. By that I mean to say, an array of existential and structural threats to America can feasibly be read into the poem but are not directly mentioned. An example of this allusion is the passage: "So, while once we asked: How could we possibly prevail over catastrophe? Now we assert: How could catastrophe possibly prevail over us?" In this passage the referents included in the term catastrophe are effectively infinite, and this is likely by design. By not articulating specific catastrophes to be overcome, Gorman is able to refer to all hardships simultaneously.

Other sections of Gorman's poem articulate the hardships of systemic racial inequality; gender inequality; and partisan division, as well as the January 6, 2021, insurrection. Alongside these explicit social contexts, I argue that the existential threats of climate change and the COVID-19 pandemic weigh heavily on the meanings of the poem. I briefly outline the contexts that Gorman references in the poem to familiarize readers with the themes of "The Hill We Climb" before entering the results section which focuses on research concepts at the expense of narrative continuity.

\section{Systemic Issues in America}

Systemic inequities pervade the socioeconomic landscape of contemporary U.S. society and have deep historical roots. Gorman indicates the importance of these inequalities and histories in the following passage: "We, the successors of a country and a 
time where a skinny Black girl, descended from slaves and raised by a single mother, can dream of becoming president, only to find herself reciting for one." The explicit mention of slavery and gender within this passage bring into the discursive context the themes of racial and gender inequalities. Later in this thesis, I argue that the grammar of this passage indicates that the present moment of America does not yet achieve the ideal future articulated by the phrase: "dream of becoming president," and therefore these inequalities persist in the present. ${ }^{4}$

State-sponsored discrimination towards People of Color historically and today undermines the economic and physical health of millions of Americans. What many refer to as America's original sin, the enslavement of Black people, has shaped America today in ways that are both very direct (e.g., population distributions and wealth distribution) and indirect (e.g., ideological, religious, and scientific justifications for the wrongful assumptions of cultural or genetic inferiority; Coleman, 2020). Well past the abolition of slavery, racial inequalities persist with ferocity, as exemplified by state policies after World War II, which undermined communities of color through divestment and redlining which reallocated wealth towards middle class, White, suburbanites (Pietila, 2010; Rothstein, 2017). Today, state-sponsored domination of People of Color continues under the purview of law enforcement (Edwards et al., 2019), voter suppression, and environmental injustices (Coleman, 2020). The historical and contemporary racial injustices of America have shaped Gorman's identity, and they are undeniable challenges of the present which Gorman sees.

\footnotetext{
${ }^{4}$ See Ideals Example 4.
} 
Racial inequalities are compounded by systemic gender inequality and wealth inequality. These inequalities are brought into the context through the above passage's mention of Gorman's “single mother." I mention a few systemic gender inequalities to make concrete some of the social challenges facing women in America. High rates of sexual violence towards women persist in the United States (Dang \& Nguyen, 2020). Gender discrimination in the United States leads to reduced access and care for women in the healthcare system (Heise et al., 2019). Intersecting with these issues is a persistent earnings gap. Women will earn and accumulate less wealth over their lifetime than men (Ruel \& Hauser, 2013), and women are more likely than men to permanently lose their jobs in the event of an emergency (Dang \& Nguyen, 2020). This inexcusably short list only scratches the surface of gender inequality in America, but it is my hope that this brief outline will bring you, the reader, and me, the researcher, into closer alignment with Gorman's frames of reference.

\section{The January 6, 2021, Insurrection and Political Polarization}

On January 6, 2021, Amanda Gorman, American citizens, and the world watched as a crowd of Trump supporters, hundreds strong, stormed the U.S. Capitol building to halt the counting of the Electoral College votes (Lakritz, 2021). Gorman seems to reference this event in the following passage: "We've seen a force that would shatter our nation, rather than share it, would destroy our country if it meant delaying democracy."5 I argue that this passage is an example of a rejected plan of action, a self-evidently bad or unacceptable outcome which must not come to pass, and its presence within the poem is indicative of the impact the insurrection had on the content of "The Hill We Climb." The

\footnotetext{
${ }^{5}$ Discussed in further detail in the results section in Negative Social Values.
} 
insurrection arose out of sustained political polarization in America, and the context of polarization is a recurring theme throughout Gorman's poem. I provide some context of polarization here to prepare readers for the results section in which I argue that the central overarching plan of the poem is to enact the means of unity ${ }^{6}$ to achieve the end-goal of pluralism $^{7}$, and the means of unity is necessary due to the social context of polarization.

The insurrection of January 6, 2021, was premeditated. Militant social movement organizations, including the "Proud Boys," answered President Donald Trump's call to gather in Washington D.C. for a demonstration (Barry et al., 2021). President Trump's rhetoric had a critical impact on January 6 , as he gave a speech questioning the results of the election before calling on the crowd to move to the Capitol building (Blake, 2021). At the Capitol building, the mob overcame security personnel and stormed into the building. The insurrectionists temporarily delayed Congress's counting of the Electoral College votes, defaced property, and stole government documents (Lakritz, 2021). The mob was responsible for killing one Capitol police officer and injuring "more than 100 police officers," and as of August 2021, four officers who defended the Capitol have committed suicide (Wolfe, 2021).

The January 6 insurrection stemmed from President Trump's rhetoric that emphasized an authoritarian, centralized source of power and change (Ritchie et al., 2018). President Trump situated himself as the person capable of "draining the swamp." His was a populist rhetoric focused on drumming up voters against the established political powers of the United States Government. President Trump promised to bring

${ }^{6}$ See Means Example 2 for an investigation of enacting unity.

${ }^{7}$ See Ends Example 3 for an investigation of pluralism. 
deliverance to a population of White conservatives interested in pursuing a "nostalgic" view of America in the 1950s (Ritchie et al., 2018, p. 248). ${ }^{8}$

To win the 2016 election, the Trump Campaign made a coalition of the bulk of the Republican and Conservative voting blocks, as indicated by a report from Pew Research Center (2018), which shows that Donald Trump captured $92 \%$ of the Republican voters and $98 \%$ of conservative voters. As McAdam and Kloos (2014) outline, the Republican and Democratic political parties have been growing ever more polarized and ideologically extreme since the 1960 s. For President Trump to win these margins in the Republican voting bloc indicates his participation in the polarized climate.

Increasing polarization has contributed to a culture of obstructionism and oneupmanship in the U.S. political system that hinders the ability of policy makers to create changes. Political polarization within the American political system and within the American populace threaten the nation's stability as well as its ability to respond to existential threats. Throughout her poem, Gorman opposes this polarization and calls on the American people to "set our differences aside," to "lay down our arms," and to build "bridges" in pursuit of a unified nation capable of overcoming the collective trials which face us.

\section{Existential Issues Facing America}

In addition to acquainting readers with the context of systemic inequalities and political polarization, I note two existential threats facing America at the time of President Biden's inauguration: climate change and COVID-19. Gorman writes, “we

\footnotetext{
${ }^{8}$ Throughout the Negative Social Values results section, I argue that Gorman's ideals, plans, and metaphors are indicative of a rejection of nostalgia in favor of progressivism.
} 
know our inaction and inertia will be the inheritance of the next generation. Our blunders become their burdens." In such passages, Gorman can refer to myriad potential outcomes at once, but none seem as pressing as the ramifications that will spawn from climate change and COVID-19.

Human-caused climate change undermines the security and economic stability of the United States (Lubchenco, 1998). The negative impacts of climate change and an increased quantity of natural disasters disproportionately affect poor families (Hallegatte \& Rozenberg, 2017). A recent study shows that air pollution is disproportionately caused by the "white majority" but is "inhaled by black and Hispanic minorities" (Tessum et al., 2019 , p. 6001). Climate change poses an existential threat to the safety and security of the United States and its people, and much depends on federal leadership for a nationwide response. Support for environmental action is, however, divided along political lines. The Republican party, from President Ronald Reagan (in office, 1981-1989) through President George W. Bush (in office, 2001-2009), has been consistently opposed to regulations designed to curb negative environmental impacts nationwide (Dunlap et al., 2001). All the while, the United Nations predicts we have less than ten years to curb climate disaster (United Nations General Assembly, 2019).

The other existential threat which faces the Biden administration is COVID-19. As of January 20, 2021, the day of Biden's inauguration, 425,543 Americans had been reported dead due to COVID-19 (Worldometer, 2021). As President Biden pointed out in his inaugural address, more Americans had at that time died due to COVID-19 than died in all of World War II. The deaths and hardships caused by COVID-19 disproportionately impact poor and minority communities who are at higher risk for underlying health issues 
(Whyte \& Zubak-Skees, 2020). The United States has not had a unified response to the pandemic, and partisan division influences the political and social responses to lockdowns and mask mandates (Gollwitzer et al., 2020). Resolving the COVID-19 pandemic and strengthening America's healthcare infrastructure are undoubtedly goals for President Biden, and it is an ever-present backdrop for "The Hill we Climb." 


\section{Researcher Positionality Statement}

Holmes (2020) argues that a positionality statement locates the researcher in relation to the research subject, and then discloses relevant researcher philosophies, researcher characteristics, and aspects of the "research-project context" in an effort to identify the impacts these had on the research process and outcomes. I follow Holmes's advice and have constructed this positionality statement according to those components. To begin, I explain my relationship to the object of research, "The Hill We Climb," by recounting why I came to focus on this text for my thesis. I then locate myself in relationship to the text's author Amanda Gorman, making note of major differences and similarities between us. In this space, I explore some personal characteristics which assist or inhibit my reading the poem according to the author's intention. Then, I lay out some of my beliefs on ontology, epistemology, and agency to convey my research philosophy. To finish, I explore the "research-project context" and attempt to understand how my need to complete a thesis and my desire to do-right by Gorman may have influenced the research.

My journey to writing this thesis and performing a textual analysis in search of values has followed a winding road full of uncertainty about my ability to find values in the social realm. For months prior to President Joe Biden's inauguration, I had been researching the theory of social values, spurred on initially by video recordings of a series of talks from Hans Joas at The Berkley Center for Religion, Peace \& World Affairs at Georgetown University, which occurred in October of 2009. In these talks Joas explored the historically contingent nature of social values and their experiential validity. Listening to his words I felt what I can only describe as a force emanating from my identity, a 
feeling I have experienced only a few times in my short 24 years of life. This feeling bubbles up sometimes in the presence of my partner or family, in the pages of George Herbert Mead's writings, and again when I watched the livestream of Amanda Gorman speaking to the American people on January 20, 2021, at the inauguration of Joe Biden. It is in these moments that I am faced with the fierce connection between myself and the world around me. These experiences seem to occur when I listen to the words of others which articulate my contexts or experiences with a near perfect resonance. George Herbert Mead, for example, provided me an articulation of human nature that overcame some of the metaphysical problems that had plagued my mind since I was first exposed to social theory. Specifically, Mead provided me a way past the issues of psychological dualism and the nature or nurture divide. As I delved into the pages of Mead's thought my life changed forever, and it was as though I could feel my identity responding with unbridled appreciation.

I felt the same resonance at President Biden's inauguration when I listened to Gorman's poem. However, I did not immediately arrive at the decision to investigate Gorman's poem after hearing it. It took me a few weeks and some encouragement from my partner to pursue "The Hill We Climb," as my source of empirical evidence. At that time, I was almost scared to listen to the poem again in fear of somehow dulling its sheen. Nonetheless, I was led by a firm intuitive belief that the poem did contain values, and that these values are part of what I felt on January 20. In retrospect, having completed the analysis, I can say with certainty that my intuition was correct. Gorman's poem contains an eloquent articulation of the current state of affairs while, at the same 
time, offering pathways to overcome the challenges which confront our nation and the world.

In many ways, I could not be further from the life experiences of Amanda Gorman. Gorman is a "skinny Black girl;" I am a big White guy. Gorman is "descended from slaves and raised by a single mother;" I descended from travelers aboard the Mayflower and was raised by a doctor and a stay-at-home mom. Gorman grew up in Los Angeles, the second largest city in the United States; I grew up in a small town in Southern Oregon with a population around twenty thousand people, less than onethousandth of the population of Los Angeles. Gorman attended an Ivy League college; I attended a state university. Gorman wins national poetry contests; I play amateur Ultimate Frisbee. Gorman aspires to be president; I aspire to be a sustainable farmer who leads pigs, not soldiers.

The differences between Gorman and me present challenges for my ability to understand and interpret "The Hill We Climb," particularly when Gorman discusses historical and contemporary injustices relating to race and gender. While I can empathize with disadvantaged groups, I have not faced this discrimination personally and I cannot know the visceral and psychological outcomes that accompany a lifetime enduring systemic disadvantage and discrimination. I also can only begin to imagine the burden and responsibility Gorman feels when she represents her race and gender on a national stage. I will never know the same depth of meaning that Gorman must feel when she speaks to a nation that denied her ancestors a public voice.

While differences between me and the author of the object of research abound, there are similarities between us which support the veracity of my interpretation of the 
text. Gorman is an activist committed to gender and racial equity as well as environmental stewardship, and while the life experiences that draw me to these areas are different, I know myself to be dedicated to the same causes. Gorman and I are both young adults who grew up in the shadow of September 11, 2001, and who are faced with a future of increasing climate and socioeconomic instability. I have knocked on hundreds of doors to activate grassroots support on issues of climate change. I have conducted research on avenues to reduce prejudicial attitudes towards racial outgroups. And my friends and family know me as a rather radical opponent to traditional gender-roles and masculine cultures. The similarities between my activist lens and Gorman's activist lens provides a bridge by which I make sense of the arguments for change that pervade "The Hill We Climb.”

In terms of my philosophical and theoretical positionality, the factors I see as most important to this research are, first, my leftist political tendencies, second, my belief in an epistemic foundation of intersubjectivity, and third, my intuitive agreement with Pragmatic Prospection. When reading the case background and results section, readers will not have trouble identifying me as a member of the Democratic party. When Amanda Gorman refers to challenges which face America as a nation, my response consistently refers to interests of the Democratic party, like climate change, rather than interests more at home in the Republican party. My own political orientation is the clearest when discussing the attempted insurrection of January 6, 2021, and former President Donald Trump, both of which spark anger in my consciousness. I have tried to tone down and eliminate my own political leanings in the results section wherever 
possible and instead attempt to highlight meanings carried by the text. I was not entirely successful.

In the realm of social sciences, I do not believe that objective knowledge is a possibility. Attempts to explain any sort of universal or ultimate truth is necessarily mediated by the human capacity for language which imbues that knowledge with subjectivity. I do, however, agree with the potential for groups of people to define knowledge intersubjectively. A process in which the goal is not to arrive at a representation of true reality but is instead to use the variety of perspectives each person brings into a discussion to arrive at an agreeable description for some element of the world. It is this orientation which encouraged me to pursue a qualitative approach to this textual analysis, as it appeared to me that the quantitative operationalizations of the Rokeach and Schwartz values surveys need revision.

As a final note on researcher positionality, writing this thesis was necessary for me to complete my degree, and it is possible that this need to produce knowledge encouraged me to draw more from the text than is warranted. That said, I do not believe that my analysis is gratuitous, and I stand by the explanations provided in the results section. Nonetheless, interpreting a text is challenging; at times, readings of the text seemed so obvious to me that it was only after feedback from an advisor or friend that I realized I was over-interpreting a phrase or passage. As those instances demonstrate, I cannot guarantee that I have sufficiently removed my own value assessments or selfmotivated interpretations from the analysis. I can, however, guarantee that this thesis was written with rigor in mind. From the first day of analysis until the last, it has been a conscious goal of mine to do right by Amanda Gorman and to do right by "The Hill We 
Climb." Both author and text have my utmost respect, and I hope that the effort I have put into my analysis demonstrates this. 


\section{Results}

In the literature review section, I outlined two conceptualizations of values to prepare for my qualitative investigation of "The Hill We Climb." First, I outlined the paradigm of Shalom Schwartz, which emphasizes universal value objects and motivational value domains. In this paradigm, values are transsituational goals which define the desirability of certain actions or outcomes, enable people to evaluate the world, and fulfill universal requirements for group coordination. Suspecting that categories of values would be insufficient to investigate values in discourse, I expanded the conceptualization of values as goals through the introduction of neurological literature broadly and the Pragmatic Prospection paradigm in particular. In this second conceptualization, I argue that values can be thought of as perceptual simulations of possible futures in which we define goal-states and devise plans to achieve them.

“The Hill we Climb" provides evidence for both forms of values, albeit in ways not always expected by theory. So, to address my Research Question (How do values manifest in "The Hill we Climb"?), my analysis suggests that values manifest as both value objects, what I term ideals, and as socially constructed plans. In this section I present results for both types of values. I call the one-word value objects which reflect the Schwartz tradition ideals. I adopt this term because this sort of value conveys a desirable quality, and they are often used as criteria of evaluation to contrast the real past or present with an ideal state. In the poem, I also found a variety of plans which employ metaphors to articulate actionable means towards a desired end. Plans convey a presumed relationship between a possible action, which I refer to as a means, and a desirable outcome, what I refer to as an end or end-goal. 
While investigating values in the poem, an unexpected category emerged:

negative social values. Gorman rejects certain ideals, and she rejects certain plans for action. These negative social values demonstrate consistent themes of rejecting nostalgia and rejecting division. By exploring what sorts of values Gorman rejects, we see a reflection of Gorman's assessment of the political landscape.

The results section is divided into five main parts. The first part investigates ideals. The second part investigates social plans. The third and fourth sections focus on the two key components of plans: means and ends, respectively. The fifth section explores two forms of negative social values: not-our-goals and goals-to-not. In each section I begin with a statement of results, then I provide representative examples as evidence and illustration. I finish each section with an analysis that argues for theoretical takeaways. Unless otherwise indicated, quoted passages are drawn from "The Hill We Climb: An Inaugural Poem for the Country" (Gorman, 2021).

\section{Form 1: Ideals}

I define Ideals as those values which are specific words that refer to a belief or social construct which may be desirable. Ideals include words that would traditionally appear on the Rokeach or Schwartz survey instruments, but I also found evidence for non-traditional ideals. Gorman uses ideals to describe and evaluate elements of the social landscape. Ideals appear as words which describe a simulated reality, largely through metaphor. Words like: "peace," "justice," "polished," "pristine," "perfect," "wounded," or "wondrous" serve to describe the feeling, quality, or state of an imagined — that is, cognitively simulated—social situation. 
As theory would suggest, ideals in this poem are used as criteria of evaluation. By this I mean, ideals carry a scale of quality from the ideal state to its implied or explicit opposite, and Gorman uses grammar to locate elements of the world on this scale. Ideals are used to describe the past, present, or future in terms of congruence with or departure from the ideal. As Ideals Example 3 describes, Gorman classifies the present as "unfinished," which describes the status of the present by contrasting it with the implied ideal of finished or complete. ${ }^{9}$ Gorman evaluates the present by locating it as aligning with or opposing an ideal.

I found a collection of traditional and non-traditional words which served as ideals. Ideals like "peace" or "justice" are the epitome of traditional value words. Other examples of traditional ideals from the text include bravery, freedom, harmony, and benevolence. Alternatively, I found non-traditional ideals which seem to fit all the theoretical criteria to be considered ideals, but which are not commonly considered a value. For example, wondrous, unbroken, whole, or polished carry implications of an ideal state which can be used to evaluate some element of the world, yet these words are not usually considered values in the Schwartz's values paradigm.

In total over 30 ideals were identified. Ideals are dispersed throughout the poem but often appeared in clusters wherein ideals play off one another to describe and qualify a simulation. Ideals arose throughout the poem; they are not confined to any one sort of statement; they appear in discussions of plans, past experiences, and in discussions of collective striving. Ideals play a prominent role in the description of end-states, wherein

\footnotetext{
9 These results reaffirm Rokeach's (1973) observation of values as inherently including reference to an "opposite or converse" state of existence (p. 5).
} 
they articulate what the desirable future looks like. The following examples are presented in the order they appear in the text.

\section{Presentation of Data}

Ideals Example 1: Traditional Ideals, Peace \& Justice. Early in the poem, Gorman employs the ideals of peace and justice to indicate the status of the past and present. The ideal of peace appears in the following passage: "We've learned that quiet isn't always peace." There are a few elements at play in this sentence. First, the structure of the sentence conveys a contrast between a shared past state of the world and the ideal state of the world. Gorman uses the collective "we've learned" to situate the simulation in the past tense while also indicating a collective ignorance or lack of knowledge. She then indicates that the historical state of "quiet"10 is not equivalent to, "isn't," the state of "peace." At this point, the manifest meaning of the passage becomes less clear. The structure of the sentence indicates "peace" is used as a description of an ideal state that contrasts with the reality of a shared history, but the passage provides little for the meaning of the words quiet or peace.

On a denotative level, contrasting quiet as not peace carries a tension. The definition of quiet is "causing no disturbance; making little sound," and this can mean being "peaceable or tranquil by nature," or as acting in a way that causes, "little or no disturbance or commotion" (Oxford English Dictionary, n.d., n.p). The structure of the phrase "quiet isn't always peace," rejects the definition of quiet as a "peaceable" nature and encourages an adoption of the latter definition: "little or no disturbance." Quiet

\footnotetext{
${ }^{10}$ Quiet is itself an ideal, a descriptive state of the world which could be used to indicate an important or goal state. This passage demonstrates how language allows people to compare ideals against one another in a social setting.
} 
denotes a sense of calm or surface level amnesty between people and groups. Peace, on the other hand, is defined as "freedom from civil unrest or disorder," and as "freedom from quarrels or dissension between individuals... a state of friendliness" (Oxford English Dictionary, n.d., n.p). So, to articulate that quiet is not peace seems to indicate that under the layer of calm persists a sense of unrest or conflict between groups.

The phrase "quiet isn’t always peace," may refer to a variety of social contexts. One potential reference may be the discourse and perception that President Obama's election marked the beginning of a "post-racial" period (Love \& Tosolt, 2010). Such perceptions are demonstrably false, with structural racism persisting, and the continued prominence of racist discourse in the American public sphere (e.g., the 2016 and 2018 election cycles). Other referents of this passage can be derived from the recent history of insurrectionists storming the U.S. Capitol building on January 6, 2021, and the embittered political campaign leading up to the attempted insurrection. These contexts are evidence for a lack of peace within America's political and public spheres. Per this reading, Gorman is reflecting on our interpretation of the world to posit that a perceived calm veneer does not equate to the ideal of peace between racial, ethnic, and political groups in America.

Overlaying the Schwartz value typology onto this example yields mixed results. The polysemic nature of the word "peace" means a simple change in the reading could locate the ideal in opposite value categories, and this runs counter to Schwartz's theory that argues the clearest distinction between values should occur for domains opposite to one another. In one reading, Gorman's "peace” may be referring to racial equality and harmony while an alternative reading might have "peace" referring to a lack of 
interpersonal violence and harmony between neighbors. ${ }^{11}$ The first reading would fall in the Societal Concern category while the second reading would land in the Security category; opposite categories according to the Schwartz typology.

The phrase, “quiet isn't always peace” provides the first example of Gorman contrasting the real with an ideal. A contrast between a reality in which the social sphere is "quiet," and an ideal state of "peace," in which intergroup and interpersonal relationships are friendly and mutually supportive. The contrast between the real and the ideal arises from the grammar of the sentence and the word "isn't." The subsequent understanding of the ideal's meaning runs into the polysemy of words and phrases and requires some degree of subjective sense making.

Gorman includes an additional ideal in the next phrase of the same sentence. It can be read, "We've learned that... the norms and notions of what 'just is' isn't always justice." This phrase demonstrates a similar structure to the previous phrase where Gorman explains the past and present realities according to a socially accepted ideal. The key linguistic indication of comparison is an "adverb of negation:" the real "isn't" the ideal (Oxford English Dictionary, n.d., n.p). Here again, analysis butts heads with the polysemy of words. The grammatical structure of the sentence only determines the presence of a comparison, but the meaning of the real and the ideal demand interpretation.

I see the real being referred to in this phrase as: "norms and notions of what "just is."” The phrase seems to denote accepted collective understandings (i.e., social norms

\footnotetext{
${ }^{11}$ Schwartz et al. (2012), seems to make an error and describe both Societal Concern and Security with the word "harmony" (p. 13; p. 59).
} 
and cognitive notions) about the state of the present reality (i.e., what "just is," the status quo). Justice, on the other hand, is defined as, the "maintenance of what is just or right by the exercise of authority or power; assignment of deserved reward or punishment," or as "the administration of law," with the notable mention of "equity" in application of the law (Oxford English Dictionary, n.d., n.p). On a denotative level, to contrast the norms of the status quo with the equitable application of the law indicates a failing of the present and past in which justice is either not being carried out or is not being carried out equitably.

When read connotatively this phrase points to the real and perceived failures of the American legal system to administer justice equitably. Systematic racism persists within the legal framework of America and within police departments (Edwards et al., 2019). In the summer of 2020 , seven months before Gorman read her poem to the American people, George Floyd, and unarmed African American man, was murdered by a police officer, sparking national and international protests. Mr. Floyd was one more on a long list of Black men and women who have died because of the unjust use of force by the American law enforcement system. It seems to me that Gorman is calling on people to recognize the difference between the reality of systematic racism and the enshrined ideal of justice.

In summary, both the ideals of peace and justice are used to evaluate the status of the present as not meeting the expectation of socially accepted values. This is accomplished through an established contrast between the established ideals of peace and justice with passivity and the acceptance of the status quo. These ideals are bound together within the same sentence and reinforce each other's evaluation of the present. 
The comparison is created by the grammar of the sentence while the subsequent interpretation of the value relies in some fashion on the human practice of making sense of language.

Ideals Example 2: Non-Traditional Value Objects, Polished \& Pristine. The ideals of polished and pristine are the first example of non-traditional value objects which abide theoretical expectations but do not fit easily into Schwartz's typology of values. Take the following phrase, "And yes, we are far from polished, far from pristine." In this phrase Gorman employs the conceptual metaphor of "far from" rather than an adverb of negation. Conceptual metaphors are a resource to explain complex social phenomenon in terms of more simple, often physical, concepts. In this case, the metaphor "far from" equates physical distance from an objective with a shortcoming of the collective "we." The ideals in this sentence are, then, being used to evaluate the present according to its departure from the ideal: the present is not polished and not pristine.

The denotation of polished as an adjective is to have a "smooth, glossy surface," and a polished object is one in which reached a perfection through completion or by being finished (Oxford English Dictionary, n.d., n.p). On the other hand. the most fitting denotation for pristine is, "of a man-made object: spotless, pure in colour; fresh, as good as new; (also) brand new, newly made, unused" (Oxford English Dictionary, n.d., n.p). Pristine, then, denotes a state of perfection that stems from the newness or unused nature of an object. On a denotative level these ideals establish an evaluative framework in which the present state of our nation is both worn down from historical use, no longer pristine, while it has also not yet attained perfection through continued use or ultimate completion, it is not yet polished. For society to be "far from" these contrasting ideal 
states indicates that the present moment is flawed, imperfect, or rough, while implying that continued work is required to alleviate these shortcomings.

On a connotative level, it is noteworthy that both polished and pristine are conceptual metaphors used by Gorman to articulate a complex state of social reality according to a description for a physical object. To say we are "far from polished, far from pristine," seems to argue that America has flaws, imperfections, and even structural damage. What specific social features Gorman refers to in this phrase are open to interpretation. For example, it may be the outward facing edifice of our nation to the world that is imperfect or it may be our internal treatment of minority populations. The surrounding discursive context provides some clarification that polished and pristine refer to political and social equality.

The surrounding text influences the reading of polished and pristine and demonstrates the relevance of the present discursive context. Preceding the phrase about polished and pristine, Gorman tells a story about Black aspirations for political equality and inclusion while recognizing historical progress from slavery. ${ }^{12}$ When placed adjacent to this story, to be "far from polished," articulates how the present state is not yet the "dream" state of political equality, but the present is still better than the past.

After the phrase about being "far from" polished and pristine, Gorman goes on to clarify how the goal state is not perfection but is instead pluralism or an inclusion of all peoples. ${ }^{13}$ To reject the ideal of perfect presents a tension with the ideals of polished or pristine as unmarred. While society may not be polished, the desirable goal is not,

\footnotetext{
12 Explained in Ideals Example 4, below.

${ }^{13}$ See Ends Example 3 for Pluralism and see Negative Social Values Example 2 for "Perfect."
} 
according to Gorman, to be glossy or perfect but rather, as becomes clear later in the poem, to be "battered but beautiful." So, the description provided by polished, pristine, and perfect are influenced by the discursive context. Furthermore, this example demonstrates how the present and past can be described in a certain way (not polished), but through argumentation an orator can question or qualify the desirability of that ideal.

In summary, despite not being considered traditional social values, words or adjectives can be positioned as desirable and used to articulate the status of the past and present in relation to that ideal. In other words, conceptual metaphors for physical qualities can function as criteria of evaluation. This example also demonstrates how the meaning of a description is bound by the discursive context and can be influenced through the linguistic decisions of a speaker or writer.

Ideals Example 3: Negative Ideals, Not Broken, Unfinished. In this example, as in Ideals Example 1 (Peace and Justice), Gorman articulates how the collective "we" has learned from the past to understand the present in a new way. The poem reads, “Somehow, we weathered and witnessed a nation that isn't broken, but simply unfinished." These words demonstrate an inversion of the previous use of ideals to explain the present moment. In Ideals Example 1 the adverb of negation, “isn't,” places the real as "not" achieving the ideal. In Ideals Example 3, Gorman uses the same adverb of negation to articulate how the present is not the negative-ideal. In effect there is a double negative that can be read in real versus ideal form as: the nation is unbroken. This inversion to negative-ideal occurs again in the second clause of the sentence when Gorman articulates that the real is the negative-ideal of "unfinished." Let me attempt to 
clarify this by introducing Rokeach's argument that values carry an internal scale of quality.

Rokeach (1973) argued that values include reference to an "opposite or converse" state of existence (p. 5). My analysis suggests that ideals can be used to articulate the conditions of a simulation by locating the simulation along the ideal's internal scale. This can be seen in the contrast of just/unjust, unbroken/broken, finished/unfinished, polished/unpolished, etc. So, when Gorman argues that the "nation isn't broken," she is rejecting the negative evaluation of the present moment and arguing instead for the good side of the scale, unbroken. Then, Gorman accepts a negative evaluation of the present moment with the statement, "simply unfinished." Ideals in discourse carry an internal scale of quality and a speaker can use grammar to identify where the present or past falls on this scale.

Read denotatively, the assessment of the present as not broken but unfinished implies a different chronological position of American society. Broken as an adjective is defined as describing some object as "separated forcibly into parts; in fragments; in pieces" (Oxford English Dictionary, n.d., n.p). To be broken indicates that at one point there was a complete whole which was then reduced to the status of broken. To reject the description of broken could mean that America never was complete. On the other hand, finished denotes something which has been, "brought to a conclusion, ended; completed" (Oxford English Dictionary, n.d., n.p). To be unfinished is, then, to have not yet arrived at a conclusion or state of completeness. To accept unfinished instead of broken provides 
a different frame of reference to make sense of challenges in the present moment, which I read as indicating that the best state of the country lies in the future rather than the past. ${ }^{14}$

Ideals Example 4: A Complex Ideal, The Presidency. Ideals Example 4 demonstrates the potential for an extended narrative to evaluate the past and present according to goals for the future. Gorman articulates this narrative in the following passage: "We, the successors of a country and a time where a skinny Black girl, descended from slaves and raised by a single mother, can dream of becoming president, only to find herself reciting for one." In a theoretical sense this is a non-traditional ideal which pushes the boundaries for criteria of evaluation in that Gorman does not use oneword adjectives as the ideal; rather it is a plan for action which creates a metaphorical story contrasting the exclusionary past and present of America with the ideal of an inclusive future. That is, Gorman contrasts the United States' exclusionary histories of slavery and gender inequalities, alongside the challenges of being a single parent, with the ideal of "becoming president", before concluding the narrative with an assessment of the present as better than the past but not yet achieving the ideal.

It is notable that the teleological scale here revolves around a nontraditional ideal: the phrase "dream of becoming president" contains a plan, a connection of means and ends, between the means of "becoming" and the end of "president." It is this plan which then serves as the ideal criteria to evaluate the present. On a denotative level this ideal can be read literally because Gorman has reported her desire to run for president (Barajas, 2021). For a Black girl to become president, as Gorman points out, exists in a direct

\footnotetext{
${ }^{14}$ This is an early, and less concrete, example of Gorman rejecting a lens of nostalgia. This is discussed further in the Negative Social Values section.
} 
tension to America's histories of slavery and gender inequalities in which neither Black people nor women were allowed the right to vote or run for political office. Gorman's evaluation concludes with the statement, "can dream of becoming president, only to find herself reciting for one." The second clause here denotes the literal present moment in which Gorman read her poem aloud to an estimated 34 million people ${ }^{15}$ at the inauguration of President Joe Biden (Koblin, 2021). Overall, this statement creates a teleology that begins with slavery and ends with to the desirable future of Gorman's presidency. Gorman locates the present as approaching but not yet attaining the ideal.

On a connotative level, this narrative and evaluation of the present can be read as a metaphor which articulates the political aspirations of women, particularly from America’s Black community. Gorman's personal pathway towards political office mirrors the status of underrepresented communities in America. Despite America's histories of slavery and gender inequalities, the future can still hold something new and profoundly different, a future of political equality. Per this reading, Gorman is articulating an aspiration for Black culture in America to be affirmed in positions of real authority, autonomy, and agency.

Ideals Example 5: An Ideal Matrix, A Better Future. Late in the poem, Gorman articulates the ideal of "better" within an important plan of the narrative: "So let us leave behind a country better than the one we were left." Contained within the grammar of the phrase is a plan which connects the means of "leave behind" with the end of "a country better than the one we were left." Within this end, Gorman positions the desirable future as "better" than the collective past. The word better is defined as, "of

\footnotetext{
${ }^{15}$ Based on TV ratings which do not include internet livestream viewers.
} 
greater excellence; of superior character or quality," or as describing that which is "more appropriate, advisable, or desirable" (Oxford English Dictionary, n.d., n.p). In the denotative sense then, the goal of this plan is to "leave behind a country" which is of a higher quality than a past version of the country.

As in previous examples, the denotative reading of the ideal of "better" makes a degree of sense on its own, but a more colorful and explanatory reading can occur when the surrounding context of the poem is taken into consideration. Ideals Example 5 occurs late in the poem, and I argue that all previously used ideals contribute to the meaning of a "better" future country. I focus on two relevant ends to elaborate this point. First, the endgoal of pluralism is a central goal of the poem, and this suggests that a better country is one in which intergroup equity and harmony prevail. Second, immediately prior to the target phrase, Gorman articulates a plan to enact the means of "mercy," "might," and "right" towards the ends of a "legacy" of "love" and "change" for the next generation. These end-goals of "love" and "change" are wrapped into the idea for what a better country is and suggest that we ought to "leave behind" a country which goes beyond peaceability between groups and arrives at a world of real fellowship. In this sense the term "better" functions as a matrix of ends because it invokes multiple interconnected goals.

The term "better," in this example, serves as a criterion of evaluation which compares the desirable future against the collective past. This example reinforces my argument that understanding the evaluative potential of an ideal requires connotation or cultural interpretations. The word "better" epitomizes evaluation, but as I have shown the 
word is polysemic and context dependent. The potential for an ideal to be polysemic calls into question arguments for universal meanings for values.

Recap of Examples. I have argued that Gorman often employs ideals in her narrative as a resource to describe elements of the world, and the examples shown above demonstrate how this descriptive quality is wrapped into evaluation. Description occurs by locating some element of the world on an ideal's continuum. Ideals function as criteria by which the past, present, and future can be located on the ideal's internal scale. At times, Gorman indicates that the real falls short of the ideal through adverbs of negation or through conceptual metaphors. I found that to understand ideals in discourse required more than a denotation or literal meaning; to adequately make sense of Gorman's evaluations requires connotation and context due to the polysemy of words.

Ideals and plans can be intertwined. As I argue in the Means and Ends results sections, ideals within plans can serve as a necessary means (i.e., a standard) or ideals can be used to describe a desirable end. Alternatively, as Ideals Example 4 shows, an entire end-goal can be used as the ideal to contrast with the past or present. This finding suggests that the concept of a criteria of evaluation may involve more rhetorical elements than only ideals. This finding also suggests that ideals or value objects do contain an internal scale of quality, but that does not necessitate that they are confined to use only as criteria of evaluation.

\section{Analysis of Ideals}

Ideals are one of the two forms of values I found within the poem. Ideals served descriptive purposes which indicate the quality or character of simulations. In other words, Gorman used ideals to make sense of the past, present, or future according to their 
alignment or departure from an ideal. Such indication of quality was accomplished with the use of grammar and conceptual metaphors. The Schwartz paradigm of values is concerned with the potential for social values to function as criteria of evaluation. Researchers in this paradigm posit social values are an element of psychologyengrained and often unconscious beliefs - that determine how individuals make sense of their world. My results support an alternative reading of Schwartz's theory in which the most important function of values is not in the unconscious; rather my results stress Schwartz's theoretical proposition that values are a discursive tool used by groups in the coordination of action. This finding aligns with the position of Hans Joas who argues that social values are vague and only influence a situation when individuals articulate them into a specific action context (1997/2000).

Ideals within the poem function to describe some quality of a simulation and thereby serve as criteria of evaluation. Quality in this sense is not generic goodness or badness; instead, Gorman's use of ideals demonstrates the potential to assign quality according to specific values. For example, the present can be assigned quality on the scale of justice, and grammar then allows for the articulation of success or failure according to that ideal. These results align with Rokeach's (1973) theoretical proposition that values contain an internal scale from a desirable state to its opposite or undesirable state.

The capacity of the human mind to evaluate some element of the world according to a given criterion appears to surpass the category of one-word value objects. As Ideals Example 4 shows, it is possible to situate a complex end-state as the criterion used to evaluate the location of the present. This capacity for evaluation according to desirable 
ends aligns with the definition of teleology as "the theory or belief that certain acts, processes, or phenomenon are to be explained in terms of intention, design, or purposiveness rather than by prior causes... the fact of being directed towards a goal" (Oxford English Dictionary, n.d., n.p). When Gorman articulates the shortcomings of the present in relationship to a desirable end goal, she is evaluating the present teleologically. In such a model, quality is assigned as success in reaching the goal, and elements of the world are evaluated according to whether they contribute or detract from the attainment of the goal state. These results suggest that social values are an important rhetorical element used for criteria of evaluation, but one-word ideals are not exhaustive of all potential forms of criteria of evaluation. Further empirical research is necessary in this area.

My results show a tension with the Schwartz paradigm of values. The Schwartz value paradigm is justified in providing value objects like peace or justice special attention due to their importance to cultures, law, and policy. However, I argue that research should seek to better understand the implications of polysemy for these shared ideals rather than make assumptions of universality. If, as scholars, we turn our gaze away from pre-formulated lists of values and towards the social reality we intend to investigate, then we may begin to see patterns in the manifestation of values, and more importantly, we may begin to identify how these ideals function within human language and therefore within groups' articulations of their experiences. Focusing on data drawn from intra-group discourse is congruent with Schwartz's proposition that values are a discursive tool used to coordinate action. Researchers must, then, turn more often to discourse to investigate important social values. 


\section{Form 2: Social Plans}

In the literature review, I outlined a conceptualization of values according to the Pragmatic Prospection paradigm. I defined values as social or shared simulations of possible future action-situations in which people identify goals and devise plans to achieve them. These futures are perceptual simulations experienced as "short films" which harness the same cognitive resources used for the construction of mental experience. Through language individuals can invoke simulations in the minds of others, and individuals within groups use this capacity of language to articulate social plans that foster coordinated action. The social articulation of potential future situations, goals, and plans constitutes social values necessary for the coordination of group life.

My results surprised me. I was expecting to find a few plans with vivid imagery used to construct long plans with thorough descriptions of the goal states. Instead, I found a veritable fountain of plans composed of interconnected means and ends, all of which are shot through with conceptual metaphors. In less than 100 lines of poetry I found roughly 21 distinct plans which employed 49 means attached to 27 ends. ${ }^{16}$ Plans manifest within the poem as articulated chains of causality concerned with directing future action towards the attainment of a goal. That is, plans connect possible actions with desirable outcomes designed to solve problems presented in the narrative. In summary, I found that "The Hill We Climb" contains a wealth of plans, each of which contains an argument to conduct certain means to arrive at certain ends.

\footnotetext{
${ }^{16}$ I say roughly because these counts contain a degree of arbitrariness because some means or ends contain multiple sub-elements which are arguably distinct. These final counts are my best judgement for when multiple statements refer to the same plan, mean, or end versus when they refer to distinct components.
} 
In this poem, plans rely on conceptual metaphors as well as ideals to describe both the potential means and the desired ends. These metaphors often invoke simulations of physical actions to describe the pursuit of desired future realities. For example, Gorman says, "we will rise from the gold-limned hills of the West!" The action to "rise" is a conceptual metaphor that uses the physical action of ascending or standing to refer to the more complex social phenomenon of activism spreading through a geographic area. Metaphorical plans were often made more explicit through extended elaboration and through rearticulation in subsequent or adjacent plans.

The patterns of causality articulated by Gorman range in complexity and in the quantity of means or ends. Most plans were short, with one-to-two means connected to one end, but at other times plans contained multiple distinct steps or more variables. By multiple steps I mean that plans could abide the following patterns: $\mathrm{A} \rightarrow \mathrm{B} \rightarrow \mathrm{C}$. In this format, $\mathrm{A}$ is a means to attain the end of $\mathrm{B}$, and then $\mathrm{B}$ is a means to attain the end of $\mathrm{C}$. Plans are easily presented in reverse: $\mathrm{C} \leftarrow \mathrm{B} \leftarrow \mathrm{A}$. Other common forms included the following: $\mathrm{A}+\mathrm{B}+\mathrm{C} \ldots \rightarrow \mathrm{N}$; or $\mathrm{A} \rightarrow \mathrm{X}+\mathrm{Y}+\mathrm{Z}$. Plans range in complexity and in the quantity of means or ends, but they are always suggestive of conducting certain actions intended to cause certain outcomes which define the desirable future.

Means and ends are defined by their location in a causal relationship. The content of a word or phrase does not determine it is a plan; it is causality which determines this categorization. So, an end to one plan can be a means for another plan. While an end can become a means, more often I found that plans reflected or repeated one another. Plans clustered together and dealt with the same issues, usually from a different point of view using a different articulation. The rearticulation of plans serves to clarify means and ends. 


\section{Presentation of Data}

Plans Example 1: Flexible Means and Ends, A Plan for the Poem. "The Hill

We Climb" opens by proposing a plan to collectively search for a solution to the hardships of our time, and the poem concludes having accomplished this plan. The opening lines read: "When day comes, we ask ourselves: where can we find light in this never-ending shade?" In this passage, Gorman provides two potential actions intended to lead to a particular outcome. Gorman offers the means: "ask ourselves" and "find," to pursue the end-goal of "light." In other words, collective reflection and searching are two possible actions by which the goal of light might be reached. Gorman has proposed a plan in the opening sentence, and by the conclusion of the poem she will have achieved her goal and found a source of light.

The word "light" in this passage is a conceptual metaphor which uses a literal or physical meaning to reference a more complex or connotative social phenomenon. The juxtaposition of light with "shade" or darkness suggests that the denotative meaning of the word refers to illumination rather than little physical weight (Oxford English Dictionary, n.d.). As a metaphorical resource, the contrast between light and dark seems to refer to the social distinction between good and bad, and to search for light is to strive for good in the abstract sense.

A connotative reading of the conceptual metaphor derived from the local discursive context and the relationship to the broader narrative of the poem reinforces the denotative reading. Gorman articulates that the search for light takes place on a new day clouded by "never-ending shade," which simulates an unnatural order of the world: daybreak without sunlight, and shade without reprieve. "Shade" in this context appears 
synonymous with darkness and suggests that the present order of the world is covered in hardship, challenges, or evil. To strive for light in the face of "never-ending shade" is therefore an attempt to overcome the evil or hardships of the present moment.

The plan to collectively search for light demonstrates how means and ends are associated by causality, and how what is an end in one plan can become a means in another plan. Gorman concludes the poem with the statement, "The new dawn blooms as we free it, for there is always light, if only we're brave enough to see it, if only we're brave enough to be it." In this phrase, Gorman articulates a desirable end for the "new dawn" to "bloom," which can be read as a success in our nation overcoming the evils and hardships carried by the term "shade." The search for a source of light is concluded with the proposition that the people of America can themselves be the source of light if we are willing to "see it" and "be it." Enacting the light exists at a junction; light is the means to overcome the shade while at the same time, enacting light is an end-goal which can be attained by achieving the standard of bravery. ${ }^{17}$

Allow me to present these plans using notation to illuminate the transformation. The initial plan of the poem is: collective reflection to $\rightarrow$ find a source of light. And the second plan concludes this operation by articulating that: being brave allows $\rightarrow$ individuals to see and enact light $\rightarrow$ to overcome societal darkness. This plan is an example of how means and ends are determined by their location within an articulated chain of causal relationships, while the content (i.e., light) can be shifted between categories depending on its position in the causal chain.

\footnotetext{
${ }^{17}$ See the Means section for a description of Standards and Means Example 3 for an analysis of bravery.
} 
Plans Example 2: Rearticulated Plans, Forge with purpose. Nearby plans

often rearticulate means and ends to create a more nuanced simulation of the actions to be taken. Plans Example 2 focuses on what I see as the ultimate objective presented in the poem: attaining the end-goal of pluralism through the means of unity. Many plans throughout the poem provide further elaboration on how unity can be enacted ${ }^{18}$ as well as how the end-goal of pluralism may be achieved. ${ }^{19}$

Two adjacent plans present Gorman's pluralism argument in this passage: "We are striving to forge our union with purpose, to compose a country committed to all cultures, colors, characters and conditions of man." The first plan of this passage proposes the means, "striving to forge," with the end of "purpose." What this end, or "purpose," is remains unclear until the second plan which articulates the means of "compose" with the end-goal of "a country committed to all cultures, colors, characters and conditions of man." These two plans mirror one another. In both cases, the means are conceptual metaphors referring to creative actions. The end-goal of "purpose" is elaborated in the second end-goal which refers to an inclusive country.

Gorman's plan for pluralism through the enaction of unity is rearticulated in subsequent plans, which further describe the actions to be taken. What began as the simple metaphors of "forge" and "compose" are replaced with actions like: "close the divide," "lay down our arms... reach out our arms to one another," and "never again sow division;" all of which describe the actions pertaining to unification in a more complex fashion.

\footnotetext{
${ }^{18}$ See Means Example 2 for further discussion of unity.

${ }^{19}$ See Ends Example 3 for further discussion of pluralism.
} 
The end-goal of pluralism, on the other hand, is rearticulated in a more referential way after its introduction. Gorman began with the end-goal of "purpose" which was then articulated as "a country committed to all cultures, colors, characters and conditions of man." This complex description of the desirable end-goal is then referred to via simpler language later in the poem: for example, "harmony for all," "our future," "the promised glade," etc. Once Gorman has established an action or outcome as important within the discursive context, she is able to refer to a previous description to either rely on the complexity of that past description or to return to a simple description and add complexity.

\section{Plans Example 3: Extended or Interconnected Plans, No-Harm, Harmony.}

While Plans Example 2 demonstrates the potential for the rearticulation of means or ends, Plans Example 3 demonstrates how plans can link together into longer chains of causality necessary to achieve the desirable end. Take the following passage: "We lay down our arms so that we can reach out our arms to one another. We seek harm to none, and harmony for all." Allow me to present the plans in notation to clarify the steps: "Lay down out arms" $\rightarrow$ "reach out our arms to one another"| "we seek" $\rightarrow$ "harm to none, and harmony for all."

The inquisitive reader will notice that the extension of plans to contain multiple steps can also be read as distinct plans in which the means of the first plan are rearticulated with the words "we seek." However, it is my understanding of this passage that the words "we seek" are more accurately understood as a use of grammar which serves to continue the chain of causality and link the initial two steps in the plan with the final ends of the plan. In other words, "we seek," functions to explain what the intention 
of the previous two means are: they are intended to achieve "harm to none, and harmony for all."

My argument for an extended chain of causality is substantiated by the continuity or logic between the steps. The means "lay down our arms" must occur to achieve the next means of "reach out our arms to one another," and abating hostilities (i.e., "lay down our arms") must also occur if we are to achieve the end "harm to none." Similarly, the end "harmony for all," is dependent on the previous means, both the abatement of hostilities and the coming together of individuals in new relationships.

Plans Example 3 demonstrates the potential for plans to link together in extended chains of causality in which Step A will lead to Step B, which will lead to Step C, etc. This example shows the potential for means to lead to a combination of multiple ends. The means of unity, i.e., the abatement of hostility and the coming together of people, will lead to combined ends of "harm to none, and harmony for all," which are mutually reinforcing end-goals, but which are nonetheless distinct elements of the desirable future.

Recap of Plans Examples. The three Plans Examples provided in this section represent how plans are defined by the articulated or assumed causality between actionable means and a desired future state. Plans Example 1 demonstrates how the content of means or ends is less important for its categorization compared to its location within a causal chain. In Plans Example 1, Gorman connects the means of collective reflection with the desired end of finding light. In this plan, light is the end-goal, and its attainment is burdened by the present context of "never-ending shade." At the end of the poem, light is transformed from a desired end into a necessary means. This new plan reads: being brave allows $\rightarrow$ individuals to see and enact light $\rightarrow$ to overcome societal 
darkness. So, "light" began as an end and is later identified as a means, the linguistic content or word remains the same but the location within a causal chain is shifted and results in a trans-categorization.

Plans Example 2 and Plans Example 3 demonstrate the potential for interactions between plans. Plans Example 2 demonstrates how adjacent plans can mirror one another and result in the rearticulation which clarifies the means or ends. In that example, the end of "purpose" is mirrored and elaborated as a pluralistic nation concerned with all peoples while the means of "forge" and "compose" are rearticulated in subsequent plans as the means of unity or unification (e.g., "close the divide" or "never again sow division"). Plans Example 3 employs a similar method of rearticulation, but I argue it results in the connection of plans into an extended chain of causality in which Step A, abating hostility $\rightarrow$ Step B, building relationships $\rightarrow$ leads to the combined ends of "harm to none, and harmony for all." Both the processes of plan rearticulation and the connection of plans into extended chains of causality create a more nuanced representation of the actions to be taken as well as the desired future to be brought about.

\section{Analysis of Plans}

Drawing from the Pragmatic Prospection Paradigm, I was sensitized to the future orientation of the human mind which attempts to simulate possible action situations, define goals within those situations, and plan actions to attain the goals. Scholars from this paradigm argue that the future is imagined using perceptual simulations that rely on the same cognitive resources used for the construction of experience in the present moment. I argued that language enables the social construction of these potential future 
situations and that researchers can conceptualize values as shared goals for the future and shared plans to attain them.

"The Hill We Climb," provided an opportunity to explore the social construction of potential future situations. My findings support the Pragmatic Prospection paradigm's proposition about the future-oriented nature of the mind because the poem was a veritable fountain of plans intended to bring about desirable futures. I found the paramount plan of the poem is to conduct the means of unity to arrive at the end-goal of pluralism, and that many other plans from the poem serve to rearticulate and elaborate the actions of unity and describe the desirable state of the world. As expected by theory, the widespread social adoption of this value could result in the coordination of group life. My methodology is not capable of quantifying the adoption or influence of this poem's values on the American populace, and further research is necessary to assess this dynamic.

Theory argues that potential future situations are experienced as perceptual simulations. It makes sense, then, that speakers would use conceptual metaphors, which Ritchie (2011) argues "activate semantic links, perceptual simulations and simulations of emotional responses.” (p. 72). By employing the resource of conceptual metaphors, Amanda Gorman can invoke simulations of complex social phenomenon like national unification with simpler physical concepts, e.g., "reach out our arms to one another." My analysis aligns with theory and suggests that conceptual metaphors are an important element of language that assist in the creation of stories about what actions ought to be conducted. The forthcoming Means Results Section delves into the role of conceptual metaphors for the simulation of plans. 
While Pragmatic Prospection provided foresight into the manifestation of values as shared plans and expected these plans to be imagined using perceptual simulations, my results provide data for the continued development of theory. Namely, my findings stress the importance of causality and the framework of plans as a combination of means and ends. I found that plans rely on the implied or explicit articulation of causality between an actionable means and a desired end. It is possible that this theoretical assertion derives tautologically from my experience with social theory which explains action in terms of means and ends. Nonetheless, I believe the presentation of results shows the linguistic presence of means aimed at desired ends, even if this linearity is not always representative of how humans act in dynamic real-world situations. Pragmatic Prospection should continue to investigate how causality is either assumed or articulated and should continue to investigate the composition of plans and how they are articulated.

In terms of chains of causality that connect actionable means with desired ends, I found that plans often rearticulate each other throughout the narrative. Rearticulation results in a more nuanced simulation or the action to be taken and the desirable future to be arrived at. There was little theoretical foreshadowing of this result, and future research should continue to explore the importance of rearticulation for the construction of shared values. My results suggest that coordination of complex social actions may be more successful if participating individuals have more congruous simulations for the actions, and that such congruence can be achieved through rearticulation or elaboration of means and ends.

Plans appear as chains of causality that can have multiple steps in which an end also serves as a means for a subsequent step in action. None of the literature I consulted 
in preparation for my investigation delved into the linguistic construction of extended plans for action, and future research should identify the forms and variations which plans can take. ${ }^{20}$ To present the steps contained within a given plan, I adopted a notation which employs arrows to indicate causality, and Pragmatic Prospection scholars should consider formalizing a system of notation to enable investigation of the forms of plans.

My argument that the content of a phrase is less indicative for it being a means or an end compared to its position in a causal chain allows for a clarification of Schwartz's argument that a means can readily become an end. Schwartz argued that the flexibility between means and ends meant that values research could do away with the distinction altogether for values. My investigation shows evidence that indeed, ideals can readily be a means or an end, however, the distinction between means and ends is still relevant to the study of values. Scholars should investigate the differences which arise when ideals appear as a means or as ends. I contribute to this investigation in the following Means section, wherein I show how Gorman employs the evaluative dimension of ideals to define necessary standards that must be met for plan to succeed. Furthermore, the Ends section investigates how ideals are often a description for what an action aspires to achieve.

\section{Means}

Pragmatic Prospection scholars argue that a core function of the human brain is to simulate possible future situations to identify desirable outcomes and devise plans to

\footnotetext{
${ }^{20}$ Potential research questions include: Under what conditions is it more persuasive to present the end before the means? How many steps can a plan include before the human brain requires technology (e.g., note-taking) to track the plan? In what situations and for what purpose would people articulate how one means can lead to a variety of ends, or vice versa?
} 
achieve goals. In essence, the brain can increase the chance for success in uncertain situations by attempting to coordinate actions ahead of time to guide the body. Pragmatic Prospection scholars are, however, not forthcoming about their theoretical lineage or linkages back to traditional Pragmatist schools of thought. American Pragmatists like John Dewey and George Herbert Mead are among those who put forward the quintessential Pragmatist argument that human consciousness is forever embedded in ongoing action situations, and that the role of the mind is to devise actions intended to attain desirable ends within a given situation. The brain's function involves the monitoring of action in the present and the reconstruction of action when unforeseen or contingent outcomes in some way disrupt the ongoing chain of actions. It is the obvious parallels between the American Pragmatist theory and Pragmatic Prospection which likely contribute to the self-given name of the latter group of scholarship, as both theories consider planning action to be an essential function of consciousness.

Dewey argued that the construction of future actions and action situations took place as imagination, and he coined the term "ends-in-view" to describe the imaginative creation of desirable ends which always takes place in a present moment constrained by circumstance (Joas, 1997/2000). Pragmatic Prospection scholars take an alternative route and ground themselves in neurological theory by adopting the term simulation rather than imagination, and they identify perceptual simulations as the central mechanism for this capacity. At some point in this transition, Pragmatic Prospection scholars dropped the terminology for means and ends to focus on the identification of goals and the designation of planned action to attain goals. Dealing with the text of "The Hill We 
Climb," I found it necessary to reintroduce the terminology for means and ends to explain how plans are presented in discourse.

Ends are in many ways synonymous with goals, but the term goal misses the intimate connection of plan components. So, while it may be possible to explain Gorman's plans as the identification of action intended to lead to goals, I found the terminology means, or actionable means, and ends, or end-states or end-goals, to be more representative of the composition of plans. Plans are marked by the causal linkage of certain means with desirable ends, and this distinction is especially helpful when the end for one plan is a means to another plan, because in these plans the goals are themselves actions to be taken in a subsequent step. I mean to say that, if both the means and the ends are actions, it is inaccurate to call one an action and the other a goal.

All told, I identified 49 means integrated into plans throughout the poem. Many plans contain multiple means, sometimes unique and sometimes rearticulated. Means are modes of conduct or possible actions which are presumed will lead to desirable states of the world. All the means I identified relied on metaphor, be it conceptual metaphors or the metaphorical language of ideals. ${ }^{21}$ Conceptual metaphors, as discussed elsewhere, are a linguistic tool used to explain social concepts in terms of simpler, more universal experiences. Almost all the conceptual metaphors used in "The Hill We Climb" were basic physical concepts. The metaphorical nature of means made some rather vague, for

\footnotetext{
${ }^{21}$ Poets and literary scholars (e.g., Robert Frost) argue that metaphor is the beating heart of poetry, and this relationship of poetry to metaphor may describe why I found that the means articulated by Gorman are all metaphorical in nature. In a more radical sense, there is an argument to be made that all language and all thought is metaphorical because it employs linguistic and conceptual tools to refer to non-linguistic actions, and if this holds true then any discussion of means whatsoever will be metaphorical until the action is performed.
} 
example, it is not immediately clear what would be required for a nation to "wade" into a "sea." Other means, however, were elaborated over the course of multiple plans using congruent metaphors to invoke more complex simulations.

Means arose within the text as descriptions of actionable behaviors, largely using conceptual metaphors (e.g., "we will rise from the sunbaked South," where the conceptual metaphor "rise" is used to describe collective action from a region of the nation), but plans are not the only location in which metaphors for action arose. I found that actions or behaviors also appear in descriptions of the past which has led to the present. I remain focused on those means which arose in relation to ends, it is noteworthy that actions, which can cause a desired change for the future, can also be an element of history which has caused the present.

There is an important interaction between two theoretical concepts which is worth discussing here. At times, the proposed means is an ideal used as a criterion of evaluation. I have taken to calling this sort of means a standard, which is an expectation that must be met if a plan is to succeed or if an end is to be brought about. Means Example 3 discusses an important standard for the narrative: bravery. My investigation is an initial step that bridges the Pragmatic Prospection paradigm with the Schwartz values paradigm. Further investigation should continue to explore how ideals can shape our understanding of goals and the actions necessary to attain them.

In summary, means are defined by their location in a causal relationship where they presumably lead to a desirable end. Means appeared as conceptual metaphors which tended to use physical motion to refer to complex social behaviors. The metaphorical nature of means resulted in differing degrees of clarity or literal-ness. In addition to 
conceptual metaphors, means employed the metaphorical language of ideals to describe how we ought to conduct ourselves or what standards must be met in pursuit of our goals.

\section{Presentation of Data}

\section{Means Example 1: Physical Conceptual Metaphors, “A Sea We Must Wade.”}

Early in the poem Gorman introduces a metaphorical narrative which describes the past and present in relationship to the future using metaphors. Take the following passage:

“The loss we carry. A sea we must wade." In this passage Gorman invokes a metaphorical narrative of deliverance that calls back to Moses's crossing the Red Sea to escape from Egypt with his people. Stories of deliverance have long been intertwined with Black culture in America as a framework for understanding and enduring the plight of slavery and Jim Crow racism. By invoking the metaphorical narrative of deliverance, Gorman can make sense of the present while inspiring an optimism for our collective ability to endure hardship to arrive at a better future.

In a more direct reading of the passage, the first sentence articulates the relationship of the past to the present moment with reference to two conceptual metaphors. The first being the concept of "loss," which is an everyday concept that here refers to collective hardships or traumas of the past. Elements of "loss" could refer to an immense range of historical hardships like the 2008 recession, the loss of life due to COVID-19, and any number of other historical moments of destruction, death, or decay. The second conceptual metaphor refers to the physical concept of "carry" to allude to the burdensome nature of historical traumas. Burdens could be psychological or socioeconomic, as for example, the effects of the 2008 recession still burden those people 
forced into bankruptcy. So, the metaphorical narrative of Means Example 1 begins with setting the context of historical suffering which continues to influence life in the present.

Within the context set by "the loss we carry," Gorman proposes a plan as selfevidently necessary when she says, "a sea we must wade." Implied in this sentence is the goal of deliverance, of reaching the opposite shore of the sea, and the articulated means to attain this end is the physical action of wading. Two conceptual metaphors appear in this sentence, one as the means and the other conveying the implied end. "Sea" here is a conceptual metaphor using a description of a geographic formation to refer to the trials and tribulations which mark the nation's future. This "sea" could refer to a variety of hardship yet to come. It may, for example, refer to the remaining fight with the COVID19 pandemic, adapting and responding to climate change, or may refer to the continued work to foster racial equality within America. The variety of potential referents included in the term "sea" indicate this end is a matrix of futures being simultaneously evoked. ${ }^{22}$ Achieving the collection of ends referred to in the crossing of the "sea" requires, according to Gorman's plan, carrying out the means of wading. To "wade" is a conceptual metaphor which uses a basic physical concept, defined as "to walk through water... which impedes motion," to refer to collective actions which overcome the hardships of the future (Oxford English Dictionary, n.d., n.p). What specific actions are included within the means of "wade" depends on the ends evoked by the word "sea." For example, wading or facing the hardships wrought by climate change will require distinct actions compared to overcoming the trials of creating racial equality. Using the conceptual metaphor of "wade" has allowed Gorman to articulate a wide variety of

\footnotetext{
${ }^{22}$ See Ends section for discussion of Matrix of Ends.
} 
potential actions within the plan of crossing the "sea." This example has demonstrated how Gorman employs conceptual metaphors to describe complex social actions in terms of simpler physical concepts, and it demonstrates how means refer to the actions to be taken while ends refer to the goal state to be achieved.

Means Example 2: The Means of Unification. In the Plans results section and elsewhere I have argued that the predominant plan of "The Hill We Climb" is to practice the means of unity towards the end-goal of pluralism. The means of unity are articulated again and again in different forms and with different metaphors throughout the poem. I focus on one passage which conveys this theme of unity in a clear manner. In this passage and elsewhere, the means of unity involve abating intergroup hostilities and instead developing new relationships to come together as one nation.

Gorman explains key elements of the means of unity here: "We close the divide because we know to put our future first, we must first put our differences aside." This plan contains two means which are positioned as synonyms, and both of which are oriented towards the same end. In notation form, this plan can be represented as: "close the divide" $\rightarrow$ "future first" $\leftarrow$ "put our differences aside." The end in this plan is another matrix which refers to a collection of desirable outcomes wrapped into the same phrase of "future first." Based on the discursive context, this end matrix may refer to achieving racial equality, overcoming the hardships of the present, creating a non-violent society, etc. In essence, the end of "our future first" refers to all the goal states of the poem wrapped into a single phrase.

To achieve this collection of end-goals, Gorman proposes the means of unification. The first phrase, "we close the divide," employs two conceptual metaphors to 
describe the means of unity. First, the conceptual metaphor, to "close," carries a few basic denotative concepts for the verb form: "to stop an opening; to shut... to fill up (a gap or open place); to bound, shut in" (Oxford English Dictionary, n.d., n.p). In the target passage the verb "close" is oriented towards the noun of "divide." The noun, divide, is defined as a "separation," or "a dividing or boundary line" (Oxford English Dictionary, n.d., n.p). So, read denotatively, this passage refers to the elimination of a separation or boundary, the coming together of what was previously two distinct parts.

As a metaphor the phrase "we close the divide," simulates the simple concept of physically joining of two parts to refer to the complex social action of reducing partisan division. An ongoing rise in polarization in the American political sphere reached a fever pitch when Donald Trump urged his supporters to storm the capitol building and interfere with the processes of democracy. Political polarization between the Democrats and Republicans has resulted in the politicization of a variety of important social issues including the response to COVID-19, belief in the anthropocentric nature of climate change, and the perceptions of racial equity. Within this polarized political context, to "close the divide" can hardly be understood in any way other than a plea to partisans of America to work together towards the best interests of the nation and to abate polarization.

The second metaphorical means of "put our differences aside," is a rearticulation of the means "close the divide," which is also oriented toward the desirable matrix of goals contained in "our future." Two conceptual metaphors within this phrase, "put" and "aside," refer to simple physical concepts that represent removing objects that block our path. The metaphor "differences" is somewhat more complex, as elements of difference 
are an everyday experience in which people, places, and things are marked by differing compositions. "Differences" as a metaphor again alludes to partisan division. Unlike "divide," which emphasizes a duality, "differences" can refer to a greater variety of social distinctions. To "put our differences aside," appears then to be a metaphor for the coming together of people from political parties, and a coming together of people of all races, ethnicities, religions, and cultures to work together to achieve the collective goals of our nation.

Means Example 2 has demonstrated the central means of unity within Gorman's poem. Other metaphors, including for example, "all the bridges we've made," continue to describe unity as an abating of hostility and a coming together to work towards the collective goals of America. Means Example 2 shows the potential for means to emphasize and clarify the intended actions through rearticulation. This example is further evidence for the importance of conceptual metaphors used as a resource to describe complex macro-political actions in terms of more basic physical actions.

Means Example 3: Using an Ideal as a Standard, Bravery. At multiple points within the poem, Gorman articulates the need to enact a given ideal to achieve a desirable end. In other words, Gorman sometimes articulates how the success of a plan relies on meeting or exceeding some criterion of evaluation. I call the use of criteria of evaluation as a necessary means a standard which must be met. Within "The Hill We Climb" there is one ideal consistently positioned as a necessary for achieving collective goals: the standard of bravery.

Bravery as an ideal appears in several passages. In "we braved the belly of the beast," bravery is a description of our past conduct as it led to the present moment. In 
"that is the promised glade, the hill we climb, if only we dare," bravery — via its synonym, daring - is positioned as necessary for success in achieving the central goals of the poem implied by the top of the "hill." In "when day comes, we step out of the shade, aflame and unafraid," Gorman seems to be describing how action is taking place in the present, and as such affirms that we are enacting bravery_-we are "unafraid." And finally, the target passage for Means Example 3: "the new dawn blooms as we free it, for there is always light, if only we're brave enough to see it, if only we're brave enough to be it." This passage articulates how success in achieving collective goals demands that we succeed according to the criterion of bravery. ${ }^{23}$

I argued in Plans Example 1 that the notation for this passage is as follows: being brave allows $\rightarrow$ individuals to see and enact light $\rightarrow$ to overcome societal darkness.

Bravery is connected to the enactment of two means: people must be brave to "see" the light and must be brave to "be" the light. This plan is then an example of complex means that rely on conceptual metaphors (i.e., "see" and "be") and an ideal metaphor (i.e., bravery) simultaneously. I next zoom into the means of accomplishing bravery to explore the use of an ideal as a standard.

On a denotative level, the adjective brave is defined as, "courageous, daring, intrepid, stout-hearted," and the verb form is defined as, "to meet or face (danger) with bravery; to encounter, defy" (Oxford English Dictionary, n.d., n.p). Per these definitions,

\footnotetext{
${ }^{23}$ One other location in the poem provides a tangential discussion for the ideal of bravery. "This is the era of just redemption. We feared at its inception... But within it we found the power to author a new chapter, to offer hope and laughter to ourselves." This passage does not explicitly refer to bravery, but it does track the historical progress of the ideal. At first, we were not achieving the standard of bravery, but through collective learning we overcame fear through hope and laughter, which alludes to achieving the end-goal bravery through given means.
} 
for the American populace to meet the expectation of bravery to overcome societal darkness would be to enact courage or fearlessness in the face of overwhelming odds or "never-ending" darkness. To be brave enough to recognize and enact our own potential for light requires, as Gorman points out, an ability to "hope" or display optimism despite the perceived odds of failure or the perceived impossibility of success. By carrying on despite these perceptions, or by subverting them, the potential for creative human action can overcome darkness.

On a connotative level, it feels as though the call for bravery to enact light and overcome "never-ending shade" is a call to combat fatalism. Systemic or structural problems which face America are often so daunting as to be overwhelming, yet these problems demand overwhelming collective action in response if they are to be resolved. Problems such as racial inequality, gender inequality, climate change and worsening environmental disasters, COVID-19, injustice in America's legal system, underfunded and deteriorating educational systems, wealth inequality, decreasing life expectancy rates, decreasing birth rates, increasing rates of deaths of despair in all age groups, houselessness crises, crumbling community and social infrastructure, household goods shortages, mass shootings, international and domestic terrorism, drug addiction, rising domestic abuse rates, national conflicts over reproductive care and abortion, gerrymandering and voter suppression, wars, veteran suicide rates, and international interference in American elections are but some of the issues facing American citizens in 2021. To even write or read this list fosters a sense of dread and helplessness, but Amanda Gorman, “a skinny Black girl, descended from slaves and raised by a single mother," calls on us to be brave. Gorman calls on all of us to "rise," to "rebuild, 
reconcile, and recover," to resist fatalism and choose to be brave so that we can work to "leave behind a country better than the one we were left."

Means Example 3 represents the potential for ideals to be employed as standards necessary to achieve success in a plan. The ideal of bravery recurs throughout the poem and indicates a mode of conduct which we must foster if we are to achieve the overarching objectives laid out in the "The Hill We Climb." This example has a mix of conceptual metaphors alongside the use of an ideal metaphor to achieve complex webs of desirable ends which derive from the discursive and political context.

Recap of Means Examples. The previous three examples have demonstrated the general formats in which means appear within "The Hill We Climb." Means in this text are all metaphorical. Most often means in the text rely on conceptual metaphors which revolve around basic physical actions while at times employing the metaphorical potential of ideals. Due to their metaphorical nature, means can be vague and may refer to a great many real-world actions. The specific actions to be taken can be elaborated through expansion of metaphorical narratives, rearticulations of means via synonyms, and through intuitive connections with the intended ends. Those metaphors which employ the language of ideals can create a standard or expectation which must be met if the desirable end is to be brought about.

\section{Analysis of Means}

My analysis indicates that plans presented in discourse involve the connection of actionable behaviors — means — which are intended to cause a desired outcome — an end. Because it is possible that the end for one plan becomes a means in another plan, the content of means or ends is less important to determining its category compared to its 
location in a causal chain. As such, research will be well served by continuing to investigate how means are communicated in discourse, and then investigating how these discursive representations of action are translated into concrete action situations.

All the means I found within the poem are metaphors, including conceptual metaphors and the metaphorical use of ideals. In other words, Gorman relies on basic physical concepts (e.g., "wade") to refer to more complex social actions involved with solving systemic issues. Because means appear as metaphors, they are vague and leave room for interpretation. Continued articulation through elaboration or rearticulation allows Gorman to clarify the actions being described. This was seen in Means Example 2, in which the means of unification to achieve collective goals are articulated in a variety of ways (e.g., the building of bridges, or the reaching out of arms to one another). The interpretation of a metaphorical means statement is also clarified by intuiting meaning based on the desirable end of the plan. In other words, the means of building bridges can be translated into a more literal reading by assessing what actions might enable people to achieve a pluralistic society. In this case, building bridges can then be understood to mean the building of interpersonal and intercommunity relationships with people from differing identity groups.

At times within the text, Gorman articulates the need to succeed according to a criterion of evaluation if a plan is to be successful, which I call standards to be met. In these cases, Gorman relies on ideals as the metaphorical language to refer to collective actions. The ideal of bravery recurs throughout the poem and demonstrates how ideals can serve as standards or expectations. Gorman argues that if we are to succeed in collective goals, be it the shining of a light in the dark or the climbing of the hill, then 
people must be brave even in the face of terrifying or overwhelming obstacles. The word bravery becomes a metaphor for social action in which people are willing to take risks and act despite their fears or trepidations. Ideals that serve as standards must be met to achieve a desired end, and this is an are an important theoretical interaction that may serve as a bridge between the Schwartz paradigm of values research and Pragmatic Prospection scholarship. Identifying the situations and conditions in which a standard is preferable to a literal or metaphorical action can illuminate how shared ideals function to coordinate group action.

\section{Ends}

While means are the cause in an articulated relationship, ends are the desired outcome. I identified 27 different ends which occurred within the plans provided by Gorman. As with means, I found that ends often range in the detail of articulation and rely on metaphors, both conceptual and ideal. Ends rely on fewer simple conceptual metaphors compared to means and instead rely on complex phrases which more often employ ideals. Ends use metaphors and the language of ideals to invoke conceptions of desirable conditions for a possible future reality.

Within the identified collection of ends, a new category emerged which amplifies the metaphorical nature of statements. I call this new category of ends: matrix. I chose this terminology based on the following definition of the word matrix: "the elements which make up a particular system, regarded as an interconnecting network" (Oxford English Dictionary, n.d., n.p). Within the text, a word or phrase is a matrix of ends when it refers to a collection of interconnected goal states which may not be expressly stated. Ends Example 2 discusses the epitome of an end matrix by investigating the word 
"victory," which refers to a collection of interconnected, yet unstated, goals. Language provides Gorman with terminology capable of referring to a collection of objectives simultaneously, and in these moments the meaning of an end is dependent on the context of the narrative. As I will show in Ends Example 2, the objectives captured by the term “victory" depend on Gorman's previous arguments; she has determined the contents of the matrix to a greater degree than the word's denotation.

\section{Presentation of Data}

\section{Ends Example 1: Complex Metaphorical Descriptions, "Move to What Shall}

Be." In the following phrase, Gorman employs a physical conceptual metaphor to describe the means which will bring the nation to a desirable end marked by a collection of ideals: "we will... move to what shall be: a country that is bruised but whole, benevolent but bold, fierce and free." The conceptual metaphor "move to" uses the basic concept of physical motion to describe the means that will bring the nation to the end of "what shall be." The end here is a matrix because "what shall be" refers to a collection of future goal states, and Gorman goes on to articulate the network which composes this matrix in a list of ideals. ${ }^{24}$

The ideals contained within the end matrix demonstrate an extended metaphor, the components of which play off one another to add nuance to the description of the desirable end. Referring to the country as bruised employs an adjective which contrasts the present with an ideal of complete health. Bruised is an indicator of physiological damage, but it is not a break or a severing. Gorman continues to reject the notion of a

\footnotetext{
${ }^{24}$ Each element of this list likely could be classified as its own goal, but I consider them subgoals contained within the end matrix. Therefore, I add only one end to the total count. This is demonstrative of the challenge I faced in quantifying malleable linguistic data.
} 
broken or severed country when she insists that America remains "whole," or achieving the state of one-ness.

Benevolent is defined as a "frame... of mind" which strives for the "good of others... charitable" (Oxford English Dictionary, n.d., n.p). As a denotative word, then, an ideal of benevolent behavior is congruent with the means of unity and the end-goal of pluralism, both of which involve inclusion and mutual support while benevolence describes action conducted with concern for the wellbeing of others.

The next ideal, "bold," exhibits a tension with benevolence. Bold is defined as, "courageous, daring, fearless; the opposite of 'timid' or 'fearful"” (Oxford English Dictionary, n.d., n.p). Bold is then a reiteration of the value of bravery which arises throughout the poem. Benevolence suggests a cool temperament in which we move cautiously to avoid negative outcomes, but Gorman qualifies this ideal and encourages a confidence of action, a sense of "bold." Pursuing one of these ideals might lead to fault in the other. Too much desire for benevolence may lead to hesitation, too much desire to be bold may lead to lapses in the treatment of others. The tension between benevolent and bold elaborates on the simulated future state.

The end matrix continues with the ideal of "fierce," which is defined as "of formidable violence and intractable temper" (Oxford English Dictionary, n.d., n.p). This denotation could indicate that fierce refers to an idolized scale in which the successful application of force is acceptable or necessary. To recognize "fierce" as an element of a desirable future may be a willingness to acknowledge that violence, or aggression more generally, may at times be a useful means. The shepherd must tend the flock and the 
nation must at times uphold its duties through violence. In this reading, "fierce" again exudes a tension with "benevolence" while concurring with the ideal of bold.

The final ideal of the matrix is "free," which is a widely recognized word in the American lexicon and legal system. Oxford English Dictionary defines free as, "not... in servitude or subjugation to another" (n.d.). The desirable future is, then, one in which America behaves in a manner selected autonomously. "Subjugation to another" may also refer to the confinement of actions according to the expectations or needs of other people. "Bold, fierce, and free" align with one another to indicate a sense of agency, confidence, and a willingness to do what is necessary, and, as with "bold" and "fierce," action which is "free" from the subjugation of others may lead to actions incongruent with the ideal of benevolence. In other words, freedom to pursue individual and collective happiness may impede on other individuals or nations.

Ends Example 1 has demonstrated the potential for a phrase, "what shall be," to refer to a matrix of interconnected goal states, and Gorman has in this case elaborated the nature of this end by interconnecting ideals. This value matrix discusses how America and Americans ought to live and conduct our future behaviors according to those proposed ideals.

Ends Example 2: Matrix of Ends, "Victory." The end matrix of victory occurs twice within the poem in the following passages: "Victorious... because we will never again sow division," and "If we're to live up to our own time, then victory won't lie in the blade, but in all the bridges we've made." In both passages there is a linking of conceptual metaphors which convey the means of unity to achieve the end of victory. In the first passage Gorman rejects the conceptual metaphor of "sow division," and thereby 
rejects the antithesis of unification. In the second passage, Gorman articulates two conceptual metaphors, the first metaphor rejects the means associated with the "blade," which denotes physical conflict or violence while referring to macropolitical intergroup hostility, in favor of the second conceptual metaphor of building "bridges," which articulates the connection of disconnected entities to describe the development of interpersonal relationships between identity groups. Overall, then, Gorman is articulating a plan which rejects intergroup hostility in favor of developing relationships as the means to attain the end of victory.

Assessing the simulation created by the term victory is assisted by a denotative reading, but the future implied by the word is determined to a greater degree by the discursive context. Victory is defined in a few relevant ways including: "having overcome an enemy or adversary in combat... supremacy or superiority as a result of armed conflict," or as "triumph or ultimate success, in any contest, struggle, or enterprise." Gorman's rejection of violent means in plans outlined above suggests that combat or armed conflict are less relevant compared to the denotative idea of triumph or success in collective struggles. To achieve victory in the lexical sense is to win the day or achieve success in one's endeavors, and in this context, victory therefore denotes that the desirable end is to win out over the struggles and hardships of the "never-ending shade." So, victory can be taken in a literal denotative sense, but the term victory refers to a great many potential action situations and desirable outcomes. I argue, then, that victory has a metaphorical or connotative reading derived from the discursive context. Victory is not just literal success; it is success in specific situations. 
The repetition of the means of unity attached to the end of victory suggests a mirroring of past plans and therefore indicates that victory mirrors past end-goals. The combination of the different end-goals contained in the word "victory" is the essence of an end-matrix. Based on the context, victory seems to entail peace between peoples and the construction of a pluralistic nation. Alongside this important narrative objective, victory can also be said to refer to all previous plans, and therefore may include reference to, for example, successfully wading the sea, finding a source of light, or harmony at the top of the "hill we climb." Regardless of the range of possible interpretations of the word "victory," the interpretation, as influenced by the discursive context, will include a variety of desirable outcomes wrapped together into a matrix. Enacting the means of unity, according to Gorman's argument, will then lead to success in the variety of goals included in this matrix.

Ends Example 3: The Heart of the Poem, Pluralism. In Plans Example 2, I argued that the following passage employs a physical conceptual metaphor as the means while providing an extended metaphorical narrative for the desirable end: "We are striving to forge our union with purpose, to compose a country committed to all cultures, colors, characters and conditions of man." In that example, I also argued that the end of "purpose" is clarified in the subsequent articulation of a "country committed," and that the resultant simulation is perhaps the most important desirable end of the entire poem. I call this end-goal pluralism. Let me explain why.

The goal is to "compose a country committed," which reads as a desire for a country which is constantly concerned with improving the status of those to which it is "committed." Gorman articulates that our country ought to be committed to four 
categories of people: "all cultures, colors, characters and conditions of man." The first two categories (cultures and colors) more clearly exist on a group level, while the second two categories (characters and conditions of man) blur the line between individual and group identification.

First, cultures are defined as "the distinctive ideas, customs, social behaviors, products, or way of life of a particular nation, society, people or period... a society or group characterized by such customs" (Oxford English Dictionary, n.d., n.p). For a country to be committed to all cultures involves inclusion towards groups with differing practices and customs, rather than exclusion or discrimination towards those cultures deemed different from the dominant way of life.

Second, to be committed to all "colors" uses a visual conceptual metaphor to refer to race and racial relationships in America. Historically to be a "colored person" was a discriminatory term, but now terms like "people of color" reappropriate the term in service to the nondominant populations. Gorman's use of the term here seems to denote an inclusive spectrum of all racial and mixed-race categories. A country "committed to all... colors" entails a country in which all racial categorizations are considered equally important in the eyes of the people, politicians, and policies of the state.

Third, "characters" conveys a sense of individual persons and their unique traits and eccentricities. This is an open category which could apply to any person living in the United States - it does not appear to denote a requirement of citizenship. Characters may also refer to established participants within a country's public sphere. Protests in Russia highlight the dangers of a government not committed to diverse political characters. For example, Alexei Navalny, an opposition leader to Putin's administration, is a citizen of a 
nation who has made multiple attempts to remove him from the public eye (Troianovski, 2021). A country in conflict with political characters is the antithesis of a country committed to all political and public characters.

Fourth, "conditions of man" blurs the line between individual and group identity. As a category it continues to express a desire for an inclusive, equal, attitude towards people in all forms of living situations. "Conditions of man" evokes simulations of individual level identity characteristics. Stereotypical "conditions" might include people with developmental disabilities; people in need of long-term medical care; people with handicaps; people with drug addictions; etc. These "conditions" could also refer to immigrants, refuges, or asylum-seekers. A country committed to individuals of all these categories is the antithesis of discriminatory regimes like the National Socialists of Nazi Germany or the Eugenicists of America and Europe.

To strive for a "country committed" to the above categories of people invokes a simulation of an inclusive society which serves all people regardless of citizenship or hierarchical position in the world. I argue that this simulation reflects the philosophical and political idea of pluralism, which the Oxford English Dictionary defines as, “autonomy for organizations and individuals in preference to monolithic state power... The presence or tolerance of a diversity of ethnic or cultural groups within a society or state... the coexistence of differing views" (n.d., n.p.). As this definition captures, a pluralistic state is one in which diverse cultures and communities live together in a state of mutual respect. Pluralism is not a melting-pot, and the goal is not to reduce or remove cultural differences in favor of a unified way of life. Quite the opposite is true; pluralism is about individuals from distinct cultures accepting the existence of differences while 
seeing those different cultures as political equals. I believe that this is the value system captured in Gorman's end-goal of “a country committed to all cultures, colors, characters, and conditions of man." A country like the one described in this passage treats all people with respect, it enables all people to participate in the political determination of the nation's future, and it provides the support necessary for all people to thrive as equal members of the nation.

Gorman is calling on those who hear or read her poem to participate in the means of unification to achieve a society in which all peoples are accepted regardless of their traditions or the color of their skin. To articulate that the means of unity must be enacted to achieve the end-goal of pluralism is an argument that pluralism does not happen of itself. To achieve an inclusive society requires effort from participants and politicians to accomplish two tasks. Pluralism requires abating hostility or conflict and instead building relationships between identity groups to foster an overarching culture of tolerance and mutual support.

Recap of Examples. The above examples demonstrate the potential for a plan's end to refer to a desirable outcome, and that these ends are often matrices which refer to networks of interconnected goal states. Ends, and especially end matrices, appear as metaphors which Gorman can elaborate through continued articulation and through repetition. In Ends Example 1 and Ends Example 3, I have argued that Gorman elaborates on the desirable end with the continued provision of metaphors. Interpretations of these metaphors stems from the denotation, the content of the plan (e.g., the recurrence of the means of unity informs the meaning of the end), alongside relevant information from the 
immediate discursive context (e.g., victory can refer to all previously proposed desirable outcomes).

\section{Analysis of Ends}

Ends are the desirable outcome for a proposed action or means and therefore comprise the objective or teleology of a plan. Socially shared plans revolve around multiple individuals adopting shared beliefs about what the future should look like and how that future can be attained. For individuals to share a belief in an end is useful for the coordination of action as it allows for the construction of means which fit an individual's unique situation. The core social plan of "The Hill We Climb" revolves around enacting the means of unity to achieve the end-goal of pluralism. Gorman articulated an extended metaphorical description for what the end-goal of pluralism is and argues that it is a "country committed to all cultures, colors, characters and conditions of man." I have argued this passage (in Ends Example 3) refers to an inclusive nation that does not discriminate against nondominant or minority groups.

To achieve the end-goal of pluralism, Gorman argues, requires the abating of intergroup and interpersonal hostility in favor of the development of new relationships and friendships (i.e., the enactment of unity). Both these ends and these means are not situation or person specific. That is to say, the achievement of pluralism through the enactment of unity must take place in "every known nook of our nation," and cannot therefore be constrained to only one place or one time. ${ }^{25}$ Creating a pluralistic nation

${ }^{25}$ This appears to represent the "transsituational" nature of values that Schwartz is concerned with; goals that matter in many or all situations a person could find themselves in. In a similar sense, the need for all people to bring this value into their life represents what Bednarek-Gilland (2015) terms the "transsubjectivity" of values. Values are concerned with action in a variety of unique contexts carried out by a variety of unique people. 
depends on individual decisions which lead to greater intergroup beneficence rather than decisions which create further intergroup hostility. For an individual to adopt this social plan would then require that individual to interpret and articulate how it is that they can enact unity within their personal social situation.

As with both ideals and means, ends appear in the text as metaphors which can be elaborated to a greater or lesser degree, and which rely on the sense making process of the reader to assume a final meaning. Certain ends rely on highly polysemic metaphors which derive most of their meaning from the immediate discursive context. Gorman uses these polysemic or vague metaphors (i.e., victory) to refer to networks of interconnected desirable outcomes, what I call end matrices. To interpret an end matrix requires an awareness of the discursive context to make sense of what the network of goals includes. For example, victory in a soccer match entails certain outcomes while victory over racial inequality entails different outcomes. In both cases, understanding the meaning of the word victory stems from the perspective of the reader or listener as well as the discursive context. Gorman can influence the content of the matrix by positioning it in relationship to certain means, and the means thereby constrain and inform the possible outcomes referred to by the matrix.

\section{Negative Social Values}

Values are commonly conceptualized as beliefs which indicate that certain objects, actions, or outcomes are desirable or good. It is important to also consider the inverse of this statement: people can have strong beliefs in the undesirability or badness of certain things. The research paradigms I have outlined in the literature review contain a foundation which supports the presence of negative social values. Rokeach recognized 
the inherent reference of a value to an "opposite or converse" state of existence (p. 5).

And the work of Joas (2013) argues that individuals' experiences serve as justification for both the self-evident goodness and the self-evident badness of elements of the world. These scholars' arguments indicate that negative social values are theoretically plausible. $^{26}$

My awareness of the potential existence of negative social values sensitized my search to the presence of bad-ness within "The Hill We Climb." I was not, however, expecting to find a theoretical distinction within the realm of negative social values, which I call goals-to-not and not-our-goals. Both forms of negative social values make use of bad-ness albeit in different ways. In total I identified eight goals-to-not and six notour-goals dispersed throughout the poem.

The first, goals-to-not, are articulations of collective goals to avoid a particular means or a particular outcome, either through the rejection of a given means or through the positive adoption of another means. For example, Gorman argues that "we will not be turned around," in our pursuit of collective objectives. Here the goal is to not enact an action (turned around), and by not performing this action we will move closer to achieving shared goals. Goals-to-not are socially acceptable goals. Groups accept ownership of the goal to avoid or disallow a certain mode of conduct or a particular end.

The second, not-our-goals, appear as wholesale rejections of values which are socially unacceptable. It is wrong or bad to own these beliefs as a goal, and, therefore, they are not our goal. The following example demonstrates this form of negative social

\footnotetext{
${ }^{26}$ At times I refer to these negative social values as rejected values because they usually manifest in the poem as a rejection of a given means, end, or ideal as unacceptable.
} 
values: Gorman says, "We've seen a force that would shatter our nation, rather than share it, would destroy our country if it meant delaying democracy." This passage describes a socially unacceptable plan which connects the means of "shatter our nation" and "destroy our country" to the end of "delaying democracy." Elsewhere in the poem Gorman argues that democracy is the indelible faith of Americans, and in the present passage she also contrasts the unacceptable plan with the acceptable means "to share." These contextual indicators are evidence that the plan to delay democracy is rejected as bad or socially unacceptable. This plan demonstrates a value which should be avoided by Americans.

Throughout the poem, negative social values abide the similar theme of rejecting the values of regressive ideologies and nostalgic orientations to political objectives. Gorman says, "we will not march back to what was, but move to what shall be," and this statement is demonstrative of the theme of rejecting nostalgia and historical states of the country. The goal is not to recreate the past, nor is it to maintain the status-quo of the present. I argue that within this consistent theme of rejecting nostalgia we see a reflection of Gorman's assessment of the political landscape of America. David Ritchie's (2018) analyses of President Trump's 2016 inaugural speech argues that President Trump employed a populist rhetoric geared towards the recreation of a nostalgic view of what America was in the 1950s. My reading of Gorman's rejection of the theme of nostalgia suggests a departure from the former President's point of view in favor of a progressive or forward-thinking value orientation in which the best time for America lies in its future rather than its past. 


\section{Presentation of Data}

Negative Social Values Example 1, Goals-to-not. The following excerpt is identifiable as a goal-to-not because the grammar of the passages indicates ownership over avoiding certain actions. The following passage rejects one conceptual metaphor plan in favor of another: Gorman says, "We will not march back to what was, but move to what shall be." The rejected element of this passage is a plan notated as: "march back" $\rightarrow$ "what was." The rejection of this plan is indicated by the adverb of negation, "not." Despite the negation of this plan, this example still represents a goal-to-not as indicated by the opening words, "we will," which suggests ownership over the rejected plan and ownership over the subsequent acceptable plan of "move to what shall be."

The phrase "march back to what was," employs the conceptual metaphor of "march back" as the means. In this case Gorman is describing collective action with the concept of physical motion through space. To "march" evokes a militaristic simulation or a uniformity of action. In the acceptable plan of "move to what shall be," Gorman replaces the metaphor of "march" with another conceptual metaphor of "move," which arguably evokes a more fluid approach. More important than the form of physical motion, the rejection of this value revolves around a rejection of directionality. The phrase "back to what was" orients the physical motion toward a historical state of the world, and Gorman replaces this end with the alternative of "to what shall be," which describes the objective for physical motion into the future. The transformation of a historically rooted end objective to a future oriented end objective denotes a rejection of a regressive plan of action in favor of a progressive plan of action. 
On a connotative level, the rejected values of "march back to what was" seems to refer to the nostalgic objectives of President Trump, described above. Gorman is therefore articulating that it is desirable for Americans to choose to pursue a different path and to actively avoid the means and ends referenced by "march back to what was." As such the articulation of values in this passage indicates that the goal is to not pursue a historical objective and instead the goal is to "move to what shall be: a country that is bruised but whole, benevolent but bold, fierce and free." I evaluated the rearticulated ends of this passage in Ends Example 1 where I argued that the choice of "bruised but whole" is indicative of an evaluation of the present as damaged but not broken or severed. Gorman's rejection of the ideal of "broken" in favor of "unfinished" provides a similar frame of reference in which America's past was at no point perfect, finished, or complete. Instead, the past and present contain faults and damage which require continued efforts to arrive at the greatest point of the nation.

Negative Social Values Example 2, Not-our-goals. In this example, Gorman rejects ownership of a plan of action when she says, "We are far from polished... But that doesn't mean we are striving to form a union that is perfect. We are striving to forge our union with purpose." The middle sentence of this quotation contains the plan "striving to form" $\rightarrow$ "a union that is perfect." By employing the negative verb "doesn't," Gorman rejects ownership of the plan and therefore positions "perfect" as not America's goal. In particular, the key rejected value in this passage is the end ideal of "perfect" rather than a rejection of the means of "striving," which is easily replaced by other physical conceptual metaphors. 
The Oxford English Dictionary defines perfect as, the state of "spiritual excellence," or "spiritually pure or blameless," and the second, less religious definition, describes perfect as "free from any imperfection or defect... cannot be improved upon" (n.d., n.p.). By rejecting these notions of an ideal state Gorman seems to posit that the goal is not to be uniform or unmarred. As indicated in the subsequent accepted plan of "forge our union with purpose," the ideal of perfect should be replaced with the ideal of pluralism. To choose pluralism while rejecting perfect denotes a desire for inclusion of different people and cultures rather than the creation of a homogeneous country without defects.

When considered within the realm of cultural interpretations, Gorman's rejection of the ideal of perfection is harder to parse as it partially rejects the language of the Preamble to the United States Constitution, which reads, "We the people of the United States, in order to form a more perfect union, establish justice, insure domestic tranquility, provide for the common defense, promote the general welfare, and secure the blessing of liberty to ourselves and our posterity, do ordain and establish this Constitution for the United States of America" (Legal Information Institute, n.d., n.p.). Gorman's statement also partially rejects the language of the former President Barrack Obama's famous “A More Perfect Union” speech of 2008 (The Wall Street Journal, 2008). I say Gorman partially rejects both the Preamble and President Obama's speech because each include the key word "more" when describing the state of perfection. The word "more" alters the denotation of the word perfect in a manner that acknowledges shortcomings of the present and the need for ever-continuing development. 
Gorman's rejection of the ideal of perfect can be made commensurate with the plan of the Preamble and President Obama if those plans are recognized as the continued striving for a better country than the present. The close association of the rejected ideal of perfect with the subsequent end objective of pluralism provides evidence for this commensurability. President Obama’s “A More Perfect Union” speech focuses on racial equality, and his argument indicates that improving racial relations and socioeconomic support for minority populations will bring America closer to a state of perfection. Gorman mirrors this value in striving for a pluralistic nation.

\section{Analysis of Negative Social Values}

Literature suggests that negative social values are theoretically expected in the form of evaluations of elements of the world as bad rather than good. In the Negative Social Values results description above I provide two theoretical statements as sources for sensitization to a values assessment of badness. I now return to each of them to assess their congruency with or departure from negative social values as I found them in the poem.

First, Rokeach recognized the inherent reference of a value to an "opposite or converse" state of existence (p. 5). The conceptualization of negative social values contained within this perspective carries some relevance to my findings if one is willing to make a few abstractions from the evidence at hand. I have argued elsewhere that Gorman's paramount plan is to enact the means of unity to arrive at the end-goal of pluralism, and per this understanding it could be argued that the consistent rejection of violence between people (e.g., "we lay down our arms") is another way to reject division. Similarly, the articulation of a rejection of nostalgic plans to return to a past state of the 
world is opposite of Gorman's desire for a progressive plan of action. A key theoretical departure from Rokeach's conception is that the reference to opposite or negative side of a value is not inherent or merely implied, instead the opposition appears as explicitly articulated contrasting plans. Furthermore, the conceptualization provided by Rokeach is more easily applied to ideals than it is to plans of action, as it is not always clear what the opposite of a plan would be. It is much easier to understand the conceptualization of an inherent reference to an opposite state of the world when considering ideals (e.g., just/unjust, peace/not-peace).

Second, the work of Joas (2013) argues that individuals' experiences serve as justification for both the self-evident goodness and the self-evident badness of elements of the world. As with the neurological theory of physiological valancing, Joas's theory here is likely more apt to describe a psychological reaction to an external stimulus rather than explain how negative values can be expressed in language. By that I mean to say that Joas's theory describes why someone would have a negative physiological reaction to the idea of destroying America as a nation based on past individual experiences (e.g., the benefits of American democracy to their wellbeing). Experiences may explain why someone might find the idea of destroying America to delay democracy as self-evidently bad.

However, Joas's theory is less apt to explain how the negativity or badness of a social value occurs in part due to intentional choices of articulation. By that I mean that Amanda Gorman does not rely solely on individual experience nor on the self-evidentiary nature of a value to indicate its badness. Instead through discursive choices (e.g., "our blunders become their [our children's] burdens") Gorman can offer explanation as to why 
some action or social object is bad. I would stress this is not a major deviation from Joas's work as he is consistently concerned with the role of articulation in both making sense of experiences and making sense of the values these experiences justify. My argument suggests that negative social values are not necessarily self-evident, and instead social articulations can indicate the position of the orator and encourage agreement from the audience. Research should then continue to investigate the linguistic mechanisms by which elements of the world can be evaluated as bad, both according to the possible functions of criteria of evaluation and through the rejection of values via intentional discursive choices.

In summary, values tend to be a vague theoretical concept, and I would stress that negative social values are an even more vague element of values scholarship. Both forms of values I have discussed whether ideals, which we use assess quality and acceptable action, or shared social plans, which guide groups into the future, are important theoretical tools to explain group behaviors. The potential for ideals and plans to exclude or reject certain behaviors will be a useful area of research to integrate into the Schwartz and Pragmatic Prospection paradigms. Understanding how and why groups prohibit certain behaviors through discourse may further develop the theoretical framework for the coordination of groups via shared values.

I have contributed one small piece to the theoretical investigation of negative social values by identifying two possible forms in which negative social values can appear in discourse. On one hand, people can articulate goals-to-not which encourage the prohibition of certain plans or actions in pursuit of desirable outcomes. Individuals and groups express ownership over goals-to-not, as it is desirable to not perform an action. 
On the other hand, people can articulate not-our-goals, which appear as a rejection of an ideal or action. For example, destroying America is not an acceptable or desirable goal according to Gorman's argument.

The theoretical distinction I have drawn here requires further investigation. It may prove easy to reformulate or reframe one of these forms of negative social values into the other form, which may suggest my theoretical distinction is unnecessary in the long-term. Investigating the key element of ownership will be essential for this exploration; under what conditions does an individual accepts a goal to avoid behavior compared to rejecting ownership of a goal altogether. 


\section{Discussion}

I begin this discussion section with the implications of my findings for the Schwartz value theory. Here I argue that the polysemy of words calls into question some of Schwartz's theoretical proposition, and I argue that the category of values Schwartz is concerned with ought to be more inclusive. My suggestions for Schwartz's theory lead into a discussion of operationalizations. There I argue continuing to investigate values in discourse will enable researchers to understand how values function as criteria of evaluation to assess the present, past, and potential future, and how values coordinate group life by aligning the frame of reference of individual group members for desirable and undesirable actions or outcomes.

After I review the Schwartz values paradigm, I turn my attention to the Pragmatic Prospection paradigm. I begin that section with an assessment of my argument that values can be conceptualized as shared simulations for future situations in which people define goals and develop plans to attain them. Then, I suggest that Pragmatic Prospection scholars should continue to investigate the potential forms in which plans arise, and how the metaphorical and polysemic nature of plans in discourse may lead to different understandings of the same plan. Deciding on terminology will assist researchers in investigating the form of plans, and I suggest that the concepts of means and ends, along with arrow notation that visually represents plan components, may serve as a jumping off point.

In the final section of this discussion, I turn to negative social values, which highlights the function of values, including ideals and plans, in the coordination of action within a group. On a theoretical level I propose two emergent forms of negative social 
values and then point out the importance of researching the intentional assignment of negative-ness through grammatical choices. I conclude the discussion section by calling on researchers to better differentiate between forms of values and suggest that a conceptbased typology will assist in future research.

\section{A Word on Limitations}

To preface these discussions, allow me to explain and explore polysemy as a limitation for my own research and for the investigation of values in discourse more broadly. McIntosh and Cuklanz (2017) describe texts as polysemic, because "they always contain a multitude of potential meanings" (p. 249). How a text is read, then, depends on the perspectives brought forth by the reader or researcher working in combination with the linguistic decisions made by the author of a text. In the case of my own research, I believe the limitation of polysemy manifests most directly in two ways: my lack of knowledge of certain cultural realms, and my reliance on research paradigms for interpretive purposes.

First, I lack an awareness of a great many different cultural histories and ways of knowing which bar me from certain readings of "The Hill We Climb." Growing up as a White male in a rural Oregon town, I have had minimal exposure to Black cultures. As my advisors and others have pointed out, Gorman's performance of "The Hill We Climb" draws from the form of Hip-hop music, and many of her narratives draw from stories of deliverance embedded in the history of Black Americans. My lack of personal experience in these realms of culture limits my ability to interpret and understand all the facets of Gorman's poem, and this has implications for the validity of my interpretations of values. 
I have missed and likely misconstrued statements of values that derive from cultures and experiences inaccessible to me.

Second, the way that polysemic texts are read depends on the perspectives brought forth by the investigator's research paradigm. By that I mean to say my interpretations of the text drew from my search for goals and for statements that seemed to orient themselves toward the future. This search acted as the framework for my interpretation of words and for the relationships between these words, and if I had been searching for different research concepts, I would have come to understand the text differently. I do not think that this invalidates my research findings because the utility or appropriateness of a theoretical concept is to be derived from its explanatory power. So, while Gorman may not have been thinking of all her statements in the vocabulary of ideals, goals, and plans when she wrote the poem, these concepts can still prove fruitful in the interpretation of Gorman's communicative act. Furthermore, there is some evidence to suggest that Gorman knowingly intended to unify the nation towards common objectives, as, for example, when Gorman said she sought to "envision a way in which our country can still come together and can still heal” (Alter, 2021). This statement references the act of creatively imagining and envisioning, a plan for the process of unification towards the goal of a healed nation. This congruency lends validity to my implementation of the concepts of ideals, plans, and goals.

Dealing with the limitations of polysemy also provides an opportunity to garner knowledge of its effects on research concepts and outcomes. While my own interpretation and reading of the text was subject to the uncertainty that arises from 
multiple possible readings of the same phrase, the research lenses I employed were also subject to this uncertainty. I have worked to integrate this uncertainty into this discussion.

\section{The Schwartz Paradigm of Values}

The Schwartz value paradigm is concerned with identifying universal types of values to understand how values contribute to a group's ability to meet universal requirements for cooperation. In constructing a theory of universal values, Schwartz made many theoretical propositions. As a research paradigm, each of these propositions must be evaluated according to empirical evidence. In one cornerstone proposition of the paradigm, Schwartz (2012) argues that value categories have clear and consistent distinctions and that a value object from one motivational domain exists in contrast with opposing domains. I argue that the polysemy of words is a limitation for this proposed categorization, and that the Schwartz value paradigm must do more to address this limitation.

For example, in the results section I explored the value of "peace," wherein I demonstrated different readings of the same value which could place the value in either the Societal Concern category or the Security category: opposite categories according to the Schwartz typology. To summarize my argument, it is possible that Gorman is referring to peace between identity groups, which reflects the Societal Concern category, and it is also possible that Gorman is referring to peace between neighbors, which reflects the Security category. The polysemy of value-words demands explanation as to how values exist in universal categories, or how a value can be said to be universal when the meaning of the word will always be context dependent. It may be possible to devise a typology of values based on content, as the Schwartz paradigm attempts, but 
accomplishing this task will require continued theoretical and methodological development to overcome the limitation of polysemy.

In another theoretical proposition, Schwartz (2012) argues that groups need values to "articulate appropriate goals," to "represent these goals mentally," and to "express them in social interaction[s]" (p. 4). By exploring values in discourse, I am better able to understand this proposition and suggest theoretical developments. I found that the form of values Schwartz is most often concerned with (e.g., value words like justice) manifest within discourse as ideals and serve descriptive purposes. Ideals can describe the desirable future and actions chosen to pursue this future, or ideals can describe the present and past via contrasting the real with the ideal. Ideals contain an internal scale from the good or desirable pole on the scale through to the bad or undesirable pole, and a speaker can describe the past, present, or future by locating it along this scale. However, according to these criteria, I also found a variety of nontraditional words which could be used in this same fashion (e.g., polished, or pristine). These words are able to express something desired or can describe an ideal state. The similarities between traditional and non-traditional one-word ideals in discourse suggests that further research is needed to define conceptual boundaries.

An alternative perspective on the above theoretical proposition argues that the goals which I found articulated in the poem were embedded in plans of action that can be much longer than one-word value objects which Schwartz endorses. When groups of people articulate goals or represent goals mentally, they are not confined to single words and can instead construct elaborate mental simulations to describe goals. If researchers are interested in the group articulation of goals necessary for coordination, then my 
analysis suggests that this research should be oriented towards the role of metaphors and narratives that groups use to convey shared simulations.

Alongside the role of values in discourse and group coordination, Schwartz argues that values serve as criteria of evaluation which people use to make sense of the world around them, where they assign goodness or badness to their world. My analysis suggests that ideals do often serve as criteria of evaluation. People can use words like peace or justice to evaluate the present moment or some action that has been done. My analysis yields two takeaways. First, I found that criteria of evaluation include an active discursive process, rather than a subconscious psychological process. By that I mean, Gorman actively brings in ideals to serve as a point of contrast between the past or present and a more desirable state of the world, and it is only through this communicative action that a given criteria influences the discursive context. This finding is akin to the argument posed by Joas (1997/2000) that social values are vague and only influence a situation when individuals articulate them into a specific action context.

Research should continue to investigate criteria of evaluation as they appear in discourse. I found that the potential for a speaker to contrast the real past or present with a more desirable state transcends one-word value objects. For example, an orator could describe an ideal state of political harmony in which historical injustices have been overcome to achieve equality between social groups, and this nuanced description of an ideal state can be set up as a point of contrast for the failure or success of the present in achieving this goal. It is possible for criteria of evaluation to rely on more complex descriptions than single words alone, and further investigation of discourse may identify 
conceptual boundaries and practical limitations for criteria of evaluation to assist individuals in making sense of their reality.

I now turn to the Schwartz's proposition that research does not need to consider the distinction between means and ends. Schwartz argues that because a means can readily become and end there is little theoretical use in considering the distinction. My analysis runs counter to this. I argue that the ideals Schwartz is concerned with are a type of linguistic content which is useful in both means and ends, but which is also useful outside the realm of plans. Further investigating how ideals can serve as means or ends will illuminate the interaction between ideals and social plans. My results have shown that when ideals are assigned as a means to attain an end, then those ideals seem to function as standards which must be met for a plan to succeed. Alternatively, the desirable nature of ideals makes them useful for describing the end-goal of a plan. So, research should continue to investigate ideals outside the confines of means and ends. That said, it will also be useful to understand what happens to an ideal when it is used for different planning purposes.

As a final point for the Schwartz paradigm, let me pose a suggestion for the operationalization of values. A predefined list of single-word value objects, as appear on the Schwartz Value Survey, is insufficient to investigate Schwartz's proposition that values are used by individuals in discourse. Based on my investigation, I suggest that researchers in this paradigm adopt a more inclusive and grounded approach to investigating values. Researchers should explore the full breadth of language used by groups. If a target value is more important to a researcher (e.g., justice) then that researcher should be interested not only in the relationship of that value word to other 
value words. The researcher should be interested in how the "value word" plays out in extended narratives and can mean different things in different contexts. Adopting an inclusive approach to the study of values which takes discourse as the site of investigation will contribute to the development of a non-reductive theory of values which is better equipped to understand and explain the role of values in group life.

\section{Values in the Pragmatic Prospection Paradigm}

I turn now to the Pragmatic Prospection paradigm. In the literature review, I argued that discourse enables the construction of a shared vision for the future alongside plans to achieve a group's goals, and that this future is experienced as perceptual simulations which can be sparked by language. This conceptualization proved useful in my analysis of "The Hill We Climb," as I found a collection of plans proposed before a large audience of Americans. These plans were often brief and relied on metaphor to spark the simulated action situation. Overall, I would recommend that researchers continue this line of investigation to further understand how goals and plans are articulated in discourse - researchers should continue to investigate: the role of metaphor, the process by which people adopt plans into their lives, the implications of polysemy for diverse understandings of the same plans, and how these plans lead to coordination of group action. Pursuing these objectives will further advance values scholarship, which has long been concerned with the role of values in coordinating group life by aligning peoples' frames of reference with what needs to be done and how it ought to be done.

My analysis suggests that simulations of plans shared via discourse manifest as the connection of actionable means with desirable outcomes or end-goals. Adopting the terminology of means and ends can serve as a bridge between Pragmatic Prospection 
scholarship and a vast array of other social theory, including American Pragmatism. John Dewey, for instance, argued for the "ends-in-view" model in which individuals, constrained to a present moment, imagine desirable futures and devise plans of action to attain their goals (Joas, 1997/2000). The concept of imagination is undoubtedly parallel to the concept of perceptual simulations. Drawing such linkages between classic social theory and the Pragmatic Prospection paradigm's argument for the future-oriented nature of the human mind will serve the broader purpose of bringing social theory and neurology into productive dialogue.

The continued investigation of social plans by Pragmatic Prospection scholars will be well served by adopting terminology to distinguish elements of plans alongside notation to demarcate these plans. Current scholarship in this paradigm uses the terminology of action and goals, but as my analysis demonstrates, the goal for an action may well be another action, in which case this terminology becomes confused. Instead, it may be more useful to use the terms means and ends to locate elements of a plan according to their location in a chain of causality. Similarly, researchers can indicate how actions are strung together into extended chains of causality using arrow notation (e.g., A $+\mathrm{B} \rightarrow \mathrm{C}$ ). Whether this notation or something else, scholars would be well served by standardizing an approach and then working to understand the many different forms and combinations that arise in discourse.

\section{Negative Social Values}

The category of negative social values exists in a variety of theoretical approaches to values. My analysis suggests that continued exploration in this area will assist researchers in understanding how values can coordinate group life by restricting the range 
of actions or goals available to group members. I found two potential forms of negative social values: goals-to-not and not-our-goals. The first, goals-to-not, are socially acceptable plans to avoid certain behaviors to arrive at desirable outcomes. This sort of negative social values is the positive adoption of a prohibition of certain behaviors. The second, not-our-goals, are socially unacceptable plans, goals, or ideals. These negative social values are rejected in their entirety, and no group member should willingly pursue them as a value (e.g., the destruction of democracy in America). These two forms of negative social values are distinguished by ownership, in the first category a group accepts ownership of a prohibition while in the second ownership is rejected. Exploring these two forms of negative social values, while searching for other forms, may improve the theoretical understanding for how groups exclude certain actions and thereby constrain individual behavior within a group.

While investigating negative social values, future research should attend to the active role of the speaker in assigning negativity. How can speakers make choices to create an argument in which some value is bad? Investigating this research question is a partial departure from past theoretical arguments for negative social values which assumes the ascription of negativity is automatic or unconscious.

\section{A Call for Conceptual Clarification}

As a final recommendation for values scholarship, I argue that researchers will benefit from a typology of values concepts. Arguments have been made that values scholarship needs to develop a singular unified concept which would encapsulate all sociological, psychological, and economic conceptualizations of values. My intuitive response is that this goal is unattainable in the current soup of value theories, as scholars 
may share the term values while investigating widely different data types or social contexts. What may prove more useful than a universal value concept is a list of value concepts which notes key differences, benefits, and intentions. For example, if scholarship continues to place the Schwartz value paradigm alongside, say, the Pragmatic Prospection paradigm, then both paradigms will be less siloed and may be used in tandem rather than in isolation. Collecting all or most value concepts into the same space and time will allow researchers to better understand the many ways that values can play out both in discourse and in conscious experience.

I have argued that Amanda Gorman's poem, "The Hill We Climb," espouses a collection of values intended to guide Americans towards a future that is more inclusive and peaceful. There is more to the poem and its performance than values, but those values which I have identified weave together into a compelling representation of the present moment, a depiction of the desirable future, and a proposed route to achieve this goal. The present moment is marked by ongoing hardships, inequalities, and lingering fears. Despite the overlay of catastrophes and existential threats, Gorman calls for bravery and decisive action to drive the nation into the future. She encourages us to set aside intergroup hostilities and instead develop new relationships so that we might achieve the long-sought goal of political pluralism and equitable governance. To achieve this goal requires a continued belief in the capacity for Democracy combined with the decision to strive for a progressive future rather than a nostalgic state. There are no guarantees of success, but one thing is certain. Achieving the future described by Gorman will require the widespread adoption of the values she poses, and, once adopted, we must 
all learn how to implement these values into our own lives in coordination with the people around us. 


\section{Conclusion}

Values are a component of groups' moral frameworks which help define what is important and thereby coordinate group action. This thesis has drawn out and implemented two conceptualizations of values that revolve around social goals to investigate Amanda Gorman's inaugural poem, “The Hill We Climb” (2021).

First, the paradigm of Shalom Schwartz and colleagues defines values as transsituational goals that capture social beliefs about the desirability of certain actions and states of the world, which are used as criteria of evaluation to make sense of the past, present, and potential futures. Schwartz argues that these goals are used by groups in discourse to coordinate action and uphold group life.

In Gorman's poem, I identified the category of Ideals as most akin to those values expected by the Schwartz paradigm. Ideals serve a descriptive purpose in discourse: they can be used to invoke ideas about the qualities or feeling of the past, present, or possible futures. Gorman uses ideals as criteria of evaluation by locating some element of the social world as congruent with or departing from the ideal. My results suggest that there may be a broader pool of words that can serve as an ideal than is currently considered by the Schwartz paradigm, and further suggests that assessing the world via criteria of evaluation may be an active discursive process, rather than an automatic, unconscious process. Continued research is needed in this paradigm to address the limitation of polysemy in understanding value words and to discern the conceptual differences between traditional value words and non-traditional ideal descriptors.

To supplement the Schwartz paradigm and ensure the appropriate tools are available for an investigation of values in discourse, I presented a second 
conceptualization of values according to the framework of Pragmatic Prospection. In this conceptualization values are defined as simulations of possible futures in which people set goals and devise plans to attain them. These plans are experienced as perceptual simulations which are shared within groups via language. Within Gorman's poem, I found a variety of plans which appear as articulated chains of causality that connect possible actions with desirable outcomes. Continuing to research values as shared goals and shared plans to attain them may contribute to scholarly understanding for the mechanisms of coordinated action. During future investigations, scholars should investigate the potential forms of plans alongside the role of language and technology in conveying these plans. Important research questions include:

How can the same linguistic representation of plans be interpreted differently depending on individual perspective; and do these differences of understanding contribute to or constrain coordinating action towards goal attainment?

During the investigation of "The Hill We Climb," the theoretical category of negative social values emerged. This category contains those values that refer to undesirable or socially unacceptable actions, plans, or goals. Further investigation of negative social values may uncover different types of negative values and determine different pathways by which these beliefs in the unacceptability of elements of the social world contribute to the social prohibition of certain behaviors, people, or things.

This thesis draws out and explores statements of values posed by poet Amanda Gorman at the Inauguration of President Joe Biden in January of 2021. I argue that the values posed in the poem weave together into an evaluation of the present alongside proposed actions that will bring the nation to a desirable future marked by peace and 
inclusivity. Gorman describes the present moment as marked by hardships and shortcomings but offers a plan to be brave and to set aside intergroup hostilities so that we might foster new relationships. Enacting these means and striving for a progressive future, rather than holding onto a nostalgic recreation of the past, will bring America closer to the end-goal of a pluralistic and equitable society. As with any value, the success of this value framework is dependent on its widespread adoption and subsequent integration into specific action contexts. 


\section{References}

Alter, A. (2021, Jan 19). Amanda Gorman captures the moment, in verse. The New York Times. https://www.nytimes.com/2021/01/19/books/amanda-gormaninauguration-hill-we-climb.html

Atzil, S., Gao, W., Fradkin, I., \& Barrett, L. (2018). Growing a social brain. Nature Human Behavior, 2(9), 624-636. https://doi.org/10.1038/s41562-018-0384-6

Barajas, J. (2021, January 17). How a 22-year-old L.A. native became Biden's inauguration poet. Los Angeles Times. https://www.latimes.com/entertainmentarts/books/story/2021-01-17/amanda-gorman-biden-inauguration-poet

Bardi, A., \& Schwartz, S. H. (2003). Values and behavior: Strength and structure of relations. Personality and Social Psychology Bulletin, 29(10), 1207-1220. https://doi.org/10.1177/0146167203254602

Barry, D., McIntire, M., \& Rosenberg, M. (2021, January 9). 'Our president wants us here': The mob that stormed the Capitol. The New York Times. https://www.nytimes.com/2021/01/09/us/capitol-rioters.html

Baumeister, R. (2016). Collective prospection: The social construction of the future. In M. Seligman, P. Railton, R. Baumeister, C. Sripada (Eds.), Homo Prospectus (pp. 133-157). Oxford University Press.

Baumeister, R., Hofmann, W., Summerville, A., Reiss, P., \& Vohs, K. (2020). Everyday thoughts in time: Experience sampling studies of mental time travel. Personality and Social Psychology Bulletin, 46(2), 1631-1648. Doi:

$10.1177 / 0146167220908411$ 
Baumeister, R., \& Masicampo, E. (2010). Conscious thought is for facilitating social and cultural interactions: How mental simulations serve the animal-culture interface. Psychological Review, 117(3), 945-971. https://doi.org/10.1037/a0019393

Baumeister, R., Vohs, K., \& Oettingen, G. (2016). Pragmatic prospection: How and why people think about the future. Review of General Psychology, 20(1), 3-16. https://doi.org/10.1037/gpr0000060

Bednarek-Gilland, A. (2015). Researching values with qualitative methods: Empathy, moral boundaries and the politics of research. Ashgate Publishing.

Biden, J. R. (2021, January 20). Inaugural Address by President Joseph R. Biden, Jr. https://www.whitehouse.gov/briefing-room/speechesremarks/2021/01/20/inaugural-address-by-president-joseph-r-biden-jr/

Bilsky, W., \& Schwartz, S. H. (1994). Values and personality. European Journal of Personality, 8, 163-181.

Blake, A. (2021, January 9). The GOP's sudden and convenient distancing from Trump's voter fraud claims. The Washington Post. https://www.washingtonpost.com/politics/2021/01/08/gops-sudden-convenientdistancing-trumps-voter-fraud-claims/

Bykowicz, J. (2021, January 20). Poet Amanda Gorman has star turn reading 'The Hill We Climb' at Biden inauguration. The Wall Street Journal. https://www.wsj.com/articles/poet-amanda-gorman-has-star-turn-at-bideninauguration-11611170398

Campbell, K. K., \& Jamieson, K. H. (2008). Presidents creating the presidency: Deeds done in words. University of Chicago Press. 
Cieciuch, J., Schwartz, S. H., \& Davidov, E. (2015). Values, social psychology of. In International Encyclopedia of the Social \& Behavioral Sciences (pp. 41-46). Elsevier.https://doi.org/10.1016/B978-0-08-097086-8.25098-8

Coleman, C. (2020). Environmental clashes on Native American land: Framing environmental and scientific disputes. Springer International Publishing.

Cuklantz, L., \& McIntosh, H. (2017). Researching mass media: Images and texts. In S. N. Hesse-Biber (Ed.). The practice of qualitative research (Third edition, pp. 246272). SAGE Publications.

Culler, J. (2010). The closeness of close reading. ADE Bulletin, 149, 20-25. DOI: 10.1632 /ade. 149.20

Curry-Stevens, A., Cross-Hammer, A., \& Coalition of Communities of Color (2011). The Native American community in Multnomah County: An unsettling profile. Portland, OR: Portland State University.

Dang, H., \& Nguyen, C. V. (2021). Gender inequality during the COVID-19 pandemic: Income, expenditure, savings, and job loss. World Development, 140, 1-10. https://doi.org/10.1016/j.worlddev.2020.105296

Damasio, A. (2018). The strange order of things: Life, feeling, and the making of cultures. Vintage Books.

Dunlap, R. E., Xiao, C., \& McCright, A. M. (2001). Politics and Environment in America: Partisan and ideological cleavages in public support for environmentalism. Environmental Politics, 10(4), 23-48.

Edwards, F., Lee, H., \& Esposito, M. (2019). Risk of being killed by police use of force in the United Stated by age, race-ethnicity, and sex. Proceedings of the National 
Academy of Sciences of the United States of America, 116(34), 16793-16798. https://doi.org/10.1073/pnas.1821204116

Gollwitzer, A., Martel, C., Brady, W. J., Parnamets, P., Freedman, I. G., Knowles, E. D., \& Van Bavel, J. J. (2020). Partisan differences in physical distancing are linked to health outcomes during the COVID-19 pandemic. Nature Human Behavior, 4, 1186-1197. https://doi.org/10.1038/s41562-020-00977-7

Gorman, A. (2021). The Hill We Climb. Viking. ISBN 9780593475271

Hallegate, S., \& Rozenberg, J. (2017). Climate change through a poverty lens. Nature Climate Change, 7, 250-256. https://doi.org/10.1038/nclimate3253

Hassan, A. (2018, February 28). A young poet's inspiration. The New York Times. https://www.nytimes.com/2018/02/28/us/a-young-poets-inspiration.html

Heise, L., Greene, M., E., Opper, N., Stavropoulou, M., Harper, C., Nascimento, M., \& Zewdie, D. (2019). Gender inequality and restrictive gender norms: Framing the challenges to health. The Lancet, 393(10189), 2440-2454. https://doi.org/10.1016/S0140-6736(19)30652-X

Hesse-Biber, S. N. (2017). The practice of qualitative research (Third edition). SAGE Publications.

Hitlin, S., \& Piliavin, J. A. (2004). Values: Reviving a dormant concept. Annual Review of Sociology, 30(1), 359-393. https://doi.org/10.1146/annurev.soc.30.012703.110640

Holmes, A. G. D. (2020). Researcher positionality-A consideration of its influences and place in qualitative research-A new researcher guide. International Journal of Education, 8(4), 1-10. https://doi.org/10.34293/education.v8i4.3232 
Holthaus, E. (2021, January 21). Amanda Gorman, the climate poet for our time. The Phoenix. https://thephoenix.substack.com/p/amanda-gorman-the-climate-poet-for Inaugural Poems in History. (n.d.). Poets.org. Retrieved April 14, 2021, from https://poets.org/inaugural-poems-history

Inskeep, S. (2021, January 19). 'History has its eyes on us:' Poet Amanda Gorman seeks right words for inauguration. National Public Radio. https://www.npr.org/sections/biden-transitionupdates/2021/01/19/958077401/history-has-its-eyes-on-us-poet-amanda-gormanseeks-right-words-for-inauguration

Joas, H. (1997/2000). The genesis of values. University of Chicago Press.

Joas, H. (2013). The sacredness of the person: A new genealogy of human rights. Georgetown University Press.

King, N., Horrocks, C., \& Brooks, J. (2018). Interviews in qualitative research. SAGE. Koblin, J. (2021, January 21). Biden's inauguration scores bigger TV ratings than Trump's. The New York Times. https://www.nytimes.com/2021/01/21/business/media/biden-inauguration-tvratings-cnn.html

Lakritz, T. (2021, January 6). Shocking photos show pro-Trump rioters in the Capitol stealing memorabilia and breaking into the desks of lawmakers. Yahoo!News. https://news.yahoo.com/shocking-photos-show-pro-trump$\underline{222205516 . h t m l \text { ?guccounter }=1}$

Legal Information Institute. (n.d.). U.S. Constitution: Preamble. Cornell Law School. $\underline{\text { https://www.law.cornell.edu/constitution/preamble }}$ 
Liu, J. (2021, January 20). Read the full text of Amanda Gorman's inaugural poem 'The Hill We Climb.' CNBC. https://www.cnbc.com/2021/01/20/amanda-gormansinaugural-poem-the-hill-we-climb-full-text.html

Love, A. B., Tosolt, B. (2010). Reality or rhetoric? Barack Obama and post-racial America. Race, Gender \& Class, 17(3), 19-37. https://www.jstor.org/stable/41674749

Lubchenco, J. (1998). Entering the century of the environments: A new social contract for science. Science, 279, 491-497. DOI: 10.1126/science.279.5350.491

Matthes, J., \& Kohring, M. (2008). The content analysis of media frames: Toward improving reliability and validity. Journal of Communication, 58(2), 258279. https://doi.org/10.1111/j.1460-2466.2008.00384.x

McAdam, D., \& Kloos, K. (2014). Deeply divided: Racial politics and social movements in post-war America. Oxford University Press.

McGann, M. (2007). Enactive theorists do it on purpose: Toward an enactive account of goals and goal-directedness. Phenomenology and the Cognitive Sciences, 6, 463483. DOI: $10.1007 / \mathrm{s} 11097-007-9074-\mathrm{y}$

Mead, G. (1934, 2015). Mind, self, and society: The definitive edition. C. Morris (Eds.), D. Huebner, \& H. Joas (Eds.). The University of Chicago Press, Chicago.

National Geographic. (n.d.). Multnomah Indians. https://web.archive.org/web/20150217181537/http://www.nationalgeographic.co $\underline{\mathrm{m} / \text { lewisandclark/record tribes_095_13_25.html }}$ 
Oxford English Dictionary. (n.d.). Benevolent. In OED.com dictionary. Retrieved July 19, 2021, from https://www-oedcom.proxy.lib.pdx.edu/view/Entry/17713?redirectedFrom=Benevolent\#eid

Oxford English Dictionary. (n.d.). Better. In OED.com dictionary. Retrieved July 19, 2021, from https://www-oedcom.proxy.lib.pdx.edu/viewdictionaryentry/Entry/18370

Oxford English Dictionary. (n.d.). Bold. In OED.com dictionary. Retrieved July 19, 2021, from https://www-oedcom.proxy.lib.pdx.edu/view/Entry/21056?rskey $=u T s U O q \&$ result=2\#eid Oxford English Dictionary. (n.d.). Brave, adjective. In OED.com dictionary. Retrieved July 19, 2021, from https://www-oedcom.proxy.lib.pdx.edu/view/Entry/22790?rskey=IIjxfL\&result=1\#eid Oxford English Dictionary. (n.d.). Brave, verb. In OED.com dictionary. Retrieved July 19, 2021, from https://www-oedcom.proxy.lib.pdx.edu/view/Entry/22791?rskey=IIjxfL\&result=2\#eid Oxford English Dictionary. (n.d.). Broken. In OED.com dictionary. Retrieved July 19, 2021, from https://www-oedcom.proxy.lib.pdx.edu/view/Entry/23637?rskey=bQgyM7\&result=2\#eid Oxford English Dictionary. (n.d.). Close. In OED.com dictionary. Retrieved July 19, 2021, from https://www-oedcom.proxy.lib.pdx.edu/view/Entry/34607?rskey=p0BM2r\&result=4\&isAdvanced $=$ false\#eid 
Oxford English Dictionary. (n.d.). Culture. In OED.com dictionary. Retrieved July 19, 2021, from https://www-oedcom.proxy.lib.pdx.edu/view/Entry/45746?rskey=GCI5uD\&result=1\&isAdvanced =false\#eid

Oxford English Dictionary. (n.d.). Divide. In OED.com dictionary. Retrieved July 19, 2021, from https://www-oedcom.proxy.lib.pdx.edu/view/Entry/56099?rskey=QqlkdR\&result=1\&isAdvanced $\underline{=\text { false\#teid }}$

Oxford English Dictionary. (n.d.). Fierce. In OED.com dictionary. Retrieved July 19, 2021, from https://www-oedcom.proxy.lib.pdx.edu/view/Entry/69972?rskey=FrwTdC\&result=2\#eid Oxford English Dictionary. (n.d.). Finished. In OED.com dictionary. Retrieved July 19, 2021, from https://www-oedcom.proxy.lib.pdx.edu/view/Entry/70447?rskey=inK9rG\&result=1\&isAdvanced= $\underline{\text { false\#teid }}$

Oxford English Dictionary. (n.d.). Free. In OED.com dictionary. Retrieved July 19, 2021, from https://www-oedcom.proxy.lib.pdx.edu/view/Entry/74375?rskey=iwzyP5\&result=1\#eid

Oxford English Dictionary. (n.d.). Justice. In OED.com dictionary. Retrieved July 19, 2021, from https://www-oedcom.proxy.lib.pdx.edu/view/Entry/102198?rskey=6KBYZM\&result=1\&isAdvanc $\underline{\text { ed }=\text { false\#eid }}$ 
Oxford English Dictionary. (n.d.). Light. In OED.com dictionary. Retrieved July 19, 2021, from https://www-oedcom.proxy.lib.pdx.edu/view/Entry/108172?rskey $=\mathrm{oFYmh} 3 \&$ result $=1$ \#eid

Oxford English Dictionary. (n.d.). Matrix. In OED.com dictionary. Retrieved July 19, 2021, from https://www-oedcom.proxy.lib.pdx.edu/view/Entry/115057?rskey=dURpP5\&result=1\&isAdvance $\underline{\mathrm{d}=\text { false\#eid }}$

Oxford English Dictionary. (n.d.). Not. In OED.com dictionary. Retrieved July 19, 2021, from https://www-oed-com.proxy.lib.pdx.edu/viewdictionaryentry/Entry/128494 Oxford English Dictionary. (n.d.). Peace. In OED.com dictionary. Retrieved July 19, 2021, from https://www-oedcom.proxy.lib.pdx.edu/view/Entry/139215?rskey=JxSRnQ\&result=1\#eid Oxford English Dictionary. (n.d.). Perfect. In OED.com dictionary. Retrieved July 19, 2021, from https://www-oedcom.proxy.lib.pdx.edu/view/Entry/140704?rskey=ds8vor\&result=1\#eid

Oxford English Dictionary. (n.d.). Pluralism. In OED.com dictionary. Retrieved July 19, 2021, from https://www-oedcom.proxy.lib.pdx.edu/view/Entry/146193?redirectedFrom=pluralism\#eid Oxford English Dictionary. (n.d.). Polished. In OED.com dictionary. Retrieved July 19, 2021, from https://www-oedcom.proxy.lib.pdx.edu/view/Entry/146868?rskey=7zF869\&result=2\#eid 
Oxford English Dictionary. (n.d.). Pristine. In OED.com dictionary. Retrieved July 19, 2021, from https://www-oedcom.proxy.lib.pdx.edu/view/Entry/151585?redirectedFrom=pristine\#eid

Oxford English Dictionary. (n.d.). Quiet. In OED.com dictionary. Retrieved July 19, 2021, from https://www-oedcom.proxy.lib.pdx.edu/view/Entry/156500?rskey=m7rn9I\&result=2\#eid

Oxford English Dictionary. (n.d.). Teleology. In OED.com dictionary. Retrieved July 19, 2021, from https://www-oedcom.proxy.lib.pdx.edu/view/Entry/198710?redirectedFrom=teleology\#eid

Oxford English Dictionary. (n.d.). Victory. In OED.com dictionary. Retrieved July 19, 2021, from https://www-oedcom.proxy.lib.pdx.edu/view/Entry/223235?rskey=RpdehE\&result=1\#eid

Oxford English Dictionary. (n.d.). Wade. In OED.com dictionary. Retrieved July 19, 2021, from https://www-oedcom.proxy.lib.pdx.edu/view/Entry/224955?rskey=Ykb7Pz\&result=3\&isAdvance $\underline{\mathrm{d}=\text { false\#eid }}$

Petronzio, M. (2017, September 17). Watch the first-ever U.S. youth poet laureate perform a stunning poem about social change. Mashable. https://mashable.com/article/amanda-gorman-us-youth-poet-laureate-social-good

Pew Research Center. (2018, August 9). An examination of the 2016 electorate, based on validated voters. https://www.pewresearch.org/politics/2018/08/09/an$\underline{\text { examination-of-the-2016-electorate-based-on-validated-voters/ }}$ 
Pietila, A. (2010). Not in my neighborhood: How bigotry shaped a great American city. Ivan R Dee, Incorporated.

Ritchie, L. D. (2011). Justice is blind: A model for analyzing metaphor transformations and narratives in actual discourse. Metaphor and the Social World, 1(1), 70-89. DOI: $10.1075 / \mathrm{msw} \cdot 1.1 .08$ rit

Ritchie, L. D. (2017). Metaphors, stories, and media framing of crime: Response to Lithwick. In M. Hanne (Ed.), Proceedings of the Stanford Symposium on Narrative and Metaphor in Law. Cambridge University Press.

Ritchie, L. D. (in press). Communication and Cognition. Cambridge University Press.

Ritchie, L. D., Feliciano, A., \& Sparks, A. (2018). Rhetorical confinement, contrasting metaphors, and cultural polarities: "Yes we can" meets "carnage in the cities." Metaphor and the Social World, 8(2), 247-266. https://doi.org/10.1075/msw.17014.rit

Rokeach, M. (1973). The nature of human values. The Free Press.

Rothstein, R. (2017). The color of law: A forgotten history of how our government segregated America. Liveright Publishing Corporation.

Ruel, E., \& Hauser, R. (2013). Explaining the gender wealth gap. Demography, 50, 11551176. DOI 10.1007/s13524-012-0182-0

Schaeffer, K. (2021, January 28). Racial, ethnic diversity increases yet again with the $117^{\text {th }}$ Congress. Pew Research Center. https://www.pewresearch.org/fact$\underline{\operatorname{tank} / 2021 / 01 / 28 / \text { racial-ethnic-diversity-increases-yet-again-with-the-117th- }}$ $\underline{\text { congress/ }}$ 
Schwartz, S. H. (1992). Universals in the content and structure of values: Theoretical advances and empirical tests in 20 countries. Advances in Experimental Social Psychology, 25, 1-65.

Schwartz, S. H. (1999). A Theory of cultural values and some implications for work. Applied Psychology: An International Review, 48(1), 23-47.

Schwartz, S. H. (2012). An overview of the Schwartz theory of basic values. Online Readings in Psychology and Culture, 2(1). https://doi.org/10.9707/2307$\underline{0919.1116}$

Schwartz, S. H. (2019). Schwartz, Shalom. In V. Zeigler-Hill, \& T. Shackelford (Eds.), Encyclopedia of Personality and Individual Differences. Springer, Cham. https://doi.org/10.1007/978-3-319-28099-8_2327-1

Schwartz, S. H., \& Bilsky, W. (1987). Toward A Universal Psychological Structure of Human Values. Journal of Personality and Social Psychology, 53(3), 550-562.

Schwartz, S. H., \& Bilsky, W. (1990). Toward a theory of the universal content and structure of values: Extensions and cross-cultural replications. Journal of Personality and Social Psychology, 58(5), 878-891.

Schwartz, S. H., Cieciuch, J., Vecchione, M., Davidov, E., Fischer, R., Beierlein, C., Ramos, A., Verkasalo, M., Lönnqvist, J. E., Demirutku, K., Dirilen-Gumus, O., \& Konty, M. (2012). Refining the theory of basic individual values. Journal of Personality and Social Psychology, 103(4), 663-688. https://doi.org/10.1037/a0029393 
Schwartz, S. H., \& Sagiv, L. (1995). Identifying culture-specifics in the content and structure of values. Journal of Cross-Cultural Psychology, 26(1), 92-116. https://doi.org/10.1177/0022022195261007

Seligman, M., Railton, P., Baumeister, R., \& Sripada, C. (2016). Homo Prospectus. Oxford University Press.

Tessum, C. W., Apte, J. S., Goodkind, A. L., Muller, N. Z., Mullins, K. A., Paolella, D. A., Polasky, S., Springer, N. P., Thakrar, S. K., Marshall, J. D., \& Hill, J. D. (2019). Inequity in consumption of goods and services adds to racial-ethnic disparities in air pollution exposure. Proceedings of the National Academy of Sciences of the United States of America, 116(13), 6001-6006. https://doi.org/10.1073/pnas.1818859116

The Klamath Tribes. (n.d.). Klamath Tribes History. https://klamathtribes.org/history/ The Oregon History Project. (2018, March 17). First Peoples in the Portland Basin. https://www.oregonhistoryproject.org/narratives/commerce-climate-andcommunity-a-history-of-portland-and-its-people/introduction-3/first-peoples-inthe-portland-basin/\#.YTFDZ51KiUk

The Wall Street Journal. (2008, March 18). Text of Obama's speech: A more perfect union. The Wall Street Journal. https://www.wsj.com/articles/BL-WB-4415

Troianovski, A. (2021, February 13). A life in opposition: Navalny's path from gadfly to heroic symbol. The New York Times. https://www.nytimes.com/2021/02/13/world/europe/navalny-russia-putin.html United Nations General Assembly. (2019). Only 11 years left to prevent irreversible damage from climate change, speakers warn during general assembly high-level 
meeting (GA/12131). United Nations, High-Level Meeting on Climate and Sustainable Development. https://www.un.org/press/en/2019/ga12131.doc.htm

Whyte, L. E., \& Zubak-Skees, C. (2020, April 1). Underlying health disparities could mean Coronavirus hits some communities harder. National Public Radio. https://www.npr.org/sections/health-shots/2020/04/01/824874977/underlyinghealth-disparities-could-mean-coronavirus-hits-some-communities-harde

Wolfe, J. (2021, August 2). Four officers who responded to U.S. Capitol attack have died by suicide. Reuters. https://www.reuters.com/world/us/officer-who-responded-uscapitol-attack-is-third-die-by-suicide-2021-08-02/

Worldometer. (2021). United States Coronavirus. Retrieved April 14, 2021, from https://www.worldometers.info/coronavirus/country/us/

Zenzen, M. J., \& Hammer, L. Z. (1978). Value measurement and existential wholeness: A critique of the Rokeachean approach to value research. The Journal of Value Inquiry, 12(2), 142-156. https://doi.org/10.1007/BF00145891 